\title{
Mechanistic and Structural Basis for the Actions of the Antibacterial Gepotidacin against Staphylococcus aureus Gyrase
}

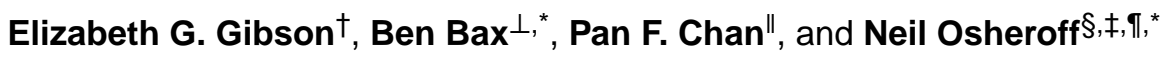 \\ tDepartment of Pharmacology, Vanderbilt University School of Medicine, Nashville, TN 37232, \\ United States, \\ §Department of Biochemistry, Vanderbilt University School of Medicine, Nashville, TN 37232 , \\ United States, \\ ¥Department of Medicine (Hematology/Oncology), Vanderbilt University School of Medicine, \\ Nashville, TN 37232, United States, \\ ${ }^{\perp}$ Department of Medicines Discovery Institute, Cardiff University, Cardiff, CF10 3AT, United \\ Kingdom, \\ "Department of Infectious Diseases Discovery, GlaxoSmithKline, Collegeville, PA, 19426, United \\ States, \\ IDepartment of VA Tennessee Valley Healthcare System, Nashville, TN 37212, United States
}

\begin{abstract}
Gepotidacin is a first-in-class triazaacenaphthylene novel bacterial topoisomerase inhibitor (NBTI). The compound has successfully completed phase II trials for the treatment of acute bacterial skin/skin structure infections and for the treatment of uncomplicated urogenital gonorrhea. It also displays robust in vitro activity against a range of wild-type and fluoroquinolone-resistant bacteria. Due to the clinical promise of gepotidacin, a detailed understanding of its interactions with its antibacterial targets is essential. Thus, we characterized the mechanism of action of gepotidacin against Staphylococcus aureus gyrase. Gepotidacin was a potent inhibitor of gyrase-catalyzed DNA supercoiling $\left(\mathrm{IC}_{50} \approx 0.047 \mu \mathrm{M}\right)$ and relaxation of positively supercoiled substrates $\left(\mathrm{IC}_{50} \approx 0.6 \mu \mathrm{M}\right.$ ). Unlike fluoroquinolones, which induce primarily double-stranded DNA breaks, gepotidacin induced high levels of gyrase-mediated single-stranded breaks. No double-stranded breaks were observed even at high gepotidacin concentration, long cleavage times, or in the presence of ATP. Moreover, gepotidacin suppressed the formation of double-stranded breaks. Gepotidacin formed gyrase-DNA cleavage complexes that were stable for $>4 \mathrm{~h}$. In vitro competition suggests that gyrase binding by gepotidacin and
\end{abstract}

*Corresponding authors: baxb@cardiff.ac.uk. Telephone: +44-(0)29-2251-1070; neil.osheroff@ vanderbilt.edu. Telephone: $+1-615-322-4338$.

Supporting Information

The Supporting Information is available free of charge on the ACS Publications website.

Potential conflicts of interest: BB and PFC have shares in GlaxoSmithKline and PFC is an employee of GlaxoSmithKline. The authors declare no other competing financial interests. 
fluoroquinolones are mutually exclusive. Finally, we determined crystal structures of gepotidacin with the $S$. aureus gyrase core fusion truncate with nicked ( $2.31 \AA$ resolution) or with intact (uncleaved) DNA ( $2.37 \AA$ resolution). In both cases, a single gepotidacin molecule was bound midway between the two scissile DNA bonds and in a pocket between the two GyrA subunits. A comparison of the two structures demonstrates conformational flexibility within the central linker of gepotidacin, which may contribute to the activity of the compound.

\section{Graphical Abstract}

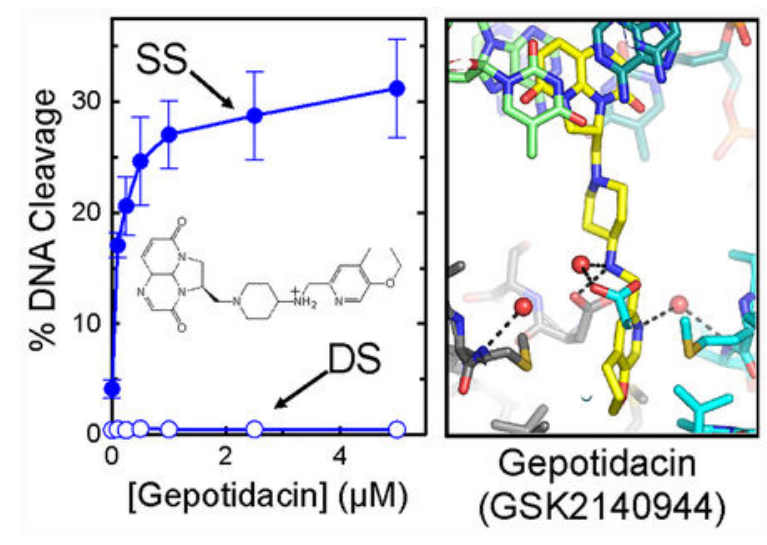

\section{Keywords}

gepotidacin; novel bacterial topoisomerase inhibitors; gyrase; Staphylococcus aureus; singlestranded DNA cleavage

There is an unmet medical need for new drugs to combat the rise in antimicrobial resistance. This is especially true for pathogens that are resistant to fluoroquinolones because of the broad use of these drugs. Fluoroquinolone resistance most often results from specific mutations in DNA gyrase or topoisomerase IV, which are the cellular targets for this drug class. $^{1-7}$

Gyrase and topoisomerase IV are ubiquitous enzymes that play essential roles in a number of critical nucleic acid processes. ${ }^{2,} 8-10$ Gyrase works in conjunction with topoisomerase I to maintain the overall negative superhelical density of bacterial chromosomes. ${ }^{8-9,11-16}$ The enzyme also is responsible for removing positive supercoils that accumulate ahead of replication forks and transcription complexes. ${ }^{8-9,11-16}$ Although topoisomerase IV may also play a role in alleviating this torsional stress, its primary function is to remove DNA knots and decatenate tangles generated during recombination and replication, respectively. 8, 17-2021-22 Gyrase and topoisomerase IV both alter DNA topology by making a transient staggered four-base pair double-stranded break in the sugar-phosphate backbone of one DNA segment, opening a gate in the cleaved double helix, and passing a second segment of DNA through the break. In order to maintain genomic integrity during the DNA cleavage event, gyrase and topoisomerase IV form covalent bonds between active site tyrosine residues and the newly formed 5'-termini of the cleaved DNA. 2, 4-5, 23-24 This covalent 
enzyme-cleaved DNA complex, which is a requisite intermediate in the catalytic cycle of these type II topoisomerases, is known as the "cleavage complex."2, 4-5, 23-24

Clinically relevant fluoroquinolones form specific interactions with gyrase and topoisomerase IV through a divalent metal ion that is chelated by the $\mathrm{C} 3 / \mathrm{C} 4$ keto acid group on the quinolone ring. ${ }^{25-31}$ The chelated metal ion is coordinated by four water molecules, two of which interact with a highly conserved serine and an acidic residue that is four amino acids upstream. ${ }^{25-31}$ Once gyrase or topoisomerase IV cut the DNA, fluoroquinolones intercalate between the bases at the cleaved scissile bonds on both strands of the double helix, ${ }^{25,}$ 30, 32-33 which stabilizes the enzyme-mediated double-stranded break. The stabilization of these cleavage complexes ultimately results in the generation of permanent double-stranded DNA breaks in the bacterial chromosome and induces the SOS response. $2-3,5-7,34-35$ It also robs the cell of the critical catalytic activities of these two enzymes, which impairs replication and transcription and can lead to catastrophic mitotic events. ${ }^{2-3,5-7}$ Both gyrase and topoisomerase IV contribute to cell death, however, the relative contributions of the two enzymes are both species and fluoroquinolone dependent. ${ }^{2-3,5-7}$

Alterations in the conserved serine or acidic residue that anchor the "water-metal ion bridge" are the most common mutations associated with fluoroquinolone resistance. ${ }^{2-3,5-7,34-35}$ The overuse/misuse of this drug class, coupled with the fact that neither of these amino acid residues are essential for enzyme function, has led to a significant rise in fluoroquinolone resistance, which is threatening the clinical usefulness of these drugs. ${ }^{2-3,5-7,35}$ Because gyrase and topoisomerase IV are highly validated antimicrobial targets, this drug resistance has led to a search for novel compounds that are structurally distinct from the fluoroquinolones, but still display activity towards these two enzymes. This search resulted in the development of a new class of compounds known as "novel bacterial topoisomerase inhibitors," or NBTIs (Figure 1). ${ }^{25}$ Although several NBTIs display potent antibacterial activity against a variety of strains, including those that are resistant to fluoroquinolones, relatively little has been published about their biochemical interactions with gyrase or topoisomerase IV. $7,25,36-43$ All reported NBTIs inhibit enzyme activity, whereas a few also enhance enzyme-mediated DNA cleavage. 7, 25, 36-42 However, in contrast to fluoroquinolones, which induce primarily double-stranded DNA breaks, these NBTIs reportedly stabilize primarily enzyme-mediated single stranded breaks. ${ }^{25,44}$

The most clinically advanced NBTI is gepotidacin (Figure 1). ${ }^{45-47}$ This first-in-class triazaacenaphthylene-based compound is one of a very few antibacterials currently in active development that acts by a novel mechanism. ${ }^{48}$ Gepotidacin has successfully completed phase II trials for the treatment of acute bacterial skin/skin structure infections (including those caused by Staphylococcus aureus) and for the treatment of uncomplicated urogenital gonorrhea with no significant adverse events. ${ }^{45-47}$ It also displays robust in vitro activity against a range of bacterial species, including fluoroquinolone-resistant strains. ${ }^{43}$

Despite the clinical promise of gepotidacin, nothing has been reported for this compound regarding its interactions with any bacterial type II topoisomerase. Therefore, we characterized the actions of gepotidacin against $S$. aureus gyrase. The compound was a potent inhibitor of gyrase catalytic activity. Furthermore, it induced high levels of gyrase- 
mediated single-stranded DNA breaks; no double-stranded breaks were observed even at high gepotidacin concentrations, extended reaction times, or in the presence of ATP. Finally, to further characterize gepotidacin interactions, we determined two crystal structures of gepotidacin with a $S$. aureus gyrase core fusion truncate. One contained nicked duplex DNA (at $2.31 \AA$ resolution) and the other contained an intact (uncleaved) DNA substrate ( $2.37 \AA$ resolution). Each structure contained a single molecule of the compound. In both cases, the left-hand side (triazaacenaphthylene) of gepotidacin sat in a pocket on the twofold axis in the DNA midway between the two DNA cleavage sites, and the right-hand side (pyranopyridine) was situated in a pocket on the twofold axis between the two GyrA subunits. Our work provides important mechanistic insight into how gepotidacin acts against its bacterial target.

\section{MATERIALS AND METHODS}

\section{Enzymes and Materials.}

Full-length wild-type $S$. aureus gyrase subunits (GyrA and GyrB, used for enzymological studies), as well as the wild-type gyrase core fusion truncate (GyrB27-A56) and a fusion truncate containing a GyrA $\mathrm{Y}^{\mathrm{Y} 23 \mathrm{~F}}$ mutation (used for structural studies) were expressed and purified as described previously. ${ }^{25}$

Negatively supercoiled pBR322 DNA was prepared from Escherichia coli using a Plasmid Mega Kit (Qiagen) as described by the manufacturer. Positively supercoiled pBR322 DNA was prepared by treating negatively supercoiled molecules with recombinant Archaeoglobus fulgidus reverse gyrase. ${ }^{49-50}$ The number of positive supercoils induced by this process is comparable to the number of negative supercoils in the original pBR322 preparations. ${ }^{49} \mathrm{In}$ the experiments that compared negatively and positively supercoiled DNA, the negatively supercoiled plasmid preparations were processed identically to the positively supercoiled molecules except that reaction mixtures did not contain reverse gyrase. Relaxed pBR322 plasmid DNA was generated by treating negatively supercoiled pBR322 with calf thymus topoisomerase I (Invitrogen) and purified as described previously. ${ }^{27}$

Gepotidacin was provided by GlaxoSmithKline. Moxifloxacin was obtained from LKT Laboratories. Gepotidacin and moxifloxacin were stored at $4{ }^{\circ} \mathrm{C}$ as $20 \mathrm{mM}$ stock solutions in $100 \%$ dimethyl sulfoxide.

\section{DNA Supercoiling and Relaxation.}

DNA supercoiling/relaxation assays were based on previously published protocols by Aldred et al. ${ }^{26,51}$ Assays contained $20 \mathrm{nM}$ gyrase, $5 \mathrm{nM}$ relaxed or positively supercoiled pBR322, $1.5 \mathrm{mM}$ ATP, $1 \mathrm{mM}$ dithiothreitol in $20 \mu \mathrm{L}$ of $50 \mathrm{mM}$ Tris- $\mathrm{HCl}$ (pH 7.7), $20 \mathrm{mM}$ $\mathrm{KCl}, 300 \mathrm{mM}$ KGlu, $5 \mathrm{mM} \mathrm{MgCl} 2$, and $0.05 \mathrm{mg} / \mathrm{mL}$ bovine serum albumin. Reactions were incubated at $37{ }^{\circ} \mathrm{C}$ for $25 \mathrm{~min}$ (DNA supercoiling assays) or $0.5 \mathrm{~min}$ (DNA relaxation assays), unless stated otherwise. The chosen assay lengths represent the minimum time required to completely negatively supercoil relaxed DNA or to relax positively supercoiled DNA in the absence of drug. Reaction mixtures were stopped by the addition of $3 \mu \mathrm{L}$ of a mixture of $0.77 \%$ SDS and $77.5 \mathrm{mM}$ EDTA. Samples were mixed with $2 \mu \mathrm{L}$ of loading 
buffer [60\% sucrose, $10 \mathrm{mM}$ Tris- $\mathrm{HCl}(\mathrm{pH} 7.9), 0.5 \%$ bromophenol blue, and $0.5 \%$ xylene cyanol FF] and were incubated at $45^{\circ} \mathrm{C}$ for 2 min before being subjected to electrophoresis on $1 \%$ agarose gels in $100 \mathrm{mM}$ Tris-borate $(\mathrm{pH} 8.3)$ and $2 \mathrm{mM}$ EDTA. Gels were stained with $1 \mu \mathrm{g} / \mathrm{mL}$ ethidium bromide for $30 \mathrm{~min}$ and DNA bands were visualized with mediumrange ultraviolet light and quantified using an Alpha Innotech digital imaging system. $\mathrm{IC}_{50}$ values were calculated using nonlinear regression, three parameter curve fit using GraphPad Prism software.

\section{DNA Cleavage.}

DNA cleavage reactions were based on the procedure of Aldred et al. ${ }^{26}$ Reactions were carried out in the presence or absence of gepotidacin or moxifloxacin and contained $75 \mathrm{nM}$ $S$. aureus gyrase $\left(\mathrm{A}_{2} \mathrm{~B}_{2}\right)$ and $10 \mathrm{nM}$ positively or negatively supercoiled pBR322 in $20 \mu \mathrm{L}$ of cleavage buffer [50 mM Tris-HCl (pH 7.5), $100 \mathrm{mM}$ KGlu, $5 \mathrm{mM} \mathrm{MgCl} 2,1 \mathrm{mM}$ dithiothreitol, and $50 \mu \mathrm{g} / \mathrm{mL}$ bovine serum albumin]. In some cases, $1.5 \mathrm{mM}$ ATP was included in reaction mixtures or the $\mathrm{MgCl}_{2}$ in the cleavage buffer was replaced with $5 \mathrm{mM}$ $\mathrm{CaCl}_{2}$. Unless stated otherwise, reactions were incubated at $37^{\circ} \mathrm{C}$ for $30 \mathrm{~min}$. Enzyme-DNA cleavage complexes were trapped by adding $2 \mu \mathrm{L}$ of $5 \%$ SDS followed by $2 \mu \mathrm{L}$ of $250 \mathrm{mM}$ EDTA and $2 \mu \mathrm{L}$ of $0.8 \mathrm{mg} / \mathrm{mL}$ Proteinase K (Sigma Aldrich). Reaction mixtures were incubated at $45^{\circ} \mathrm{C}$ for $30 \mathrm{~min}$ to digest gyrase. Samples were mixed with $2 \mu \mathrm{L}$ of loading buffer and were incubated at $45^{\circ} \mathrm{C}$ for 2 min before loading onto $1 \%$ agarose gels. Reaction products were subjected to electrophoresis in a buffer of $40 \mathrm{mM}$ Tris-acetate $(\mathrm{pH} \mathrm{8.3)}$ and 2 mM EDTA that contained $0.5 \mu \mathrm{g} / \mathrm{mL}$ ethidium bromide. DNA bands were visualized and quantified as described above. DNA single- or double-stranded cleavage was monitored by the conversion of supercoiled plasmid to nicked or linear molecules, respectively, and quantified in comparison to a control reaction in which an equal amount of DNA was digested by EcoRI (New England BioLabs). $\mathrm{EC}_{50}$ values were calculated using nonlinear regression, three parameter curve fit using GraphPad Prism software.

\section{Stability of Gyrase-DNA Cleavage Complexes.}

The persistence of gyrase-DNA cleavage complexes in the absence or presence of gepotidacin or moxifloxacin was determined using the procedure of Aldred et al. ${ }^{26}$ Initial reaction mixtures contained $375 \mathrm{nM}$ gyrase, $50 \mathrm{nM}$ negatively supercoiled pBR322, and 5 $\mu \mathrm{M}$ gepotidacin or $25 \mu \mathrm{M}$ moxifloxacin in $20 \mu \mathrm{L}$ of cleavage buffer. In experiments carried out in the absence of drug, the $\mathrm{MgCl}_{2}$ in the cleavage buffer was replaced with $5 \mathrm{mM} \mathrm{CaCl}_{2}$ to increase baseline levels of DNA cleavage.$^{51-52}$ Reaction mixtures were incubated at $37^{\circ} \mathrm{C}$ for $30 \mathrm{~min}$ to allow cleavage complexes to form, and were then diluted 20 -fold with $37{ }^{\circ} \mathrm{C}$ cleavage buffer that lacked divalent metal ion. Samples $(20 \mu \mathrm{L})$ were removed at times ranging from 0-240 min. DNA cleavage was stopped and samples were processed, visualized, and quantified as described above. Levels of gepotidacin-induced single-stranded or moxifloxacin-induced double-stranded DNA cleavage were set to $100 \%$ at time zero, as was enzyme-mediated DNA cleavage in the absence of drug. The persistence (stability) of cleavage complexes was determined by the loss of single- or double-stranded DNA cleavage, respectively, over time. 


\section{Crystallization of Gepotidacin in Complexes with S. aureus Gyrase.}

Crystals of gepotidacin with the $S$. aureus gyrase core fusion truncate (GyrB27-A56) that contained a GyrA ${ }^{\mathrm{Y} 123 \mathrm{~F}}$ mutation and 20-12p-8 duplex DNA were grown by microbatch under oil and frozen as described previously (Table S1). ${ }^{25,53}$ The position of the nicks were at the scissile bonds. A schematic of the gyrase truncate is shown in Figure S1. The 20$12 \mathrm{p}-8$ is a 20 mer DNA duplex made by annealing complementary 8 mers and 12 mers such that the four base-pair overhang from the 12 mers is complementary (Table S2; Watson strand: 5'-AGCCGTAG-3' + 5'-GTACCTACGGCT-3'; Crick strand: 5'-AGCCGTAG-3' + 5'-GTACCTACGGCT-3'). ${ }^{25}$ The 12 mer contains a 5' phosphate moiety, equivalent to the scissile phosphate, but not covalently linked to the $3{ }^{\prime} \mathrm{OH}$ of the preceding nucleotide or Tyr123 of GyrA. The symmetric doubly nicked DNA was used because it has been optimized to provide diffractable crystals with NBTIs. ${ }^{25}, 53$ Gepotidacin also was crystallized with the wild-type $S$. aureus gyrase core fusion truncate and an intact (uncleaved) symmetric homoduplex DNA (Table S2; 20-444T). Note that in crystal structures of NBTIs formed with asymmetric DNA substrates (Table S2), the DNA has static disorder around the same axis of the complex. ${ }^{53-55}$

Data to $2.31 \AA$ were collected on a single frozen crystal of gepotidacin with the $S$. aureus gyrase core fusion truncate containing a GyrA ${ }^{\mathrm{Y} 123 \mathrm{~F}}$ mutation and the symmetrically nicked 20-12p-8 duplex DNA on beamline ID23-2 at the ESRF on a Mar 225 CCD. ${ }^{25}$ Data were processed and merged with HKL and SCALEPACK ${ }^{56}$, the structure was solved by rigid body refinement from other structures in the same cell (PDB codes: 2 xcs, 5iwi), ${ }^{25}$ and refined with refmac ${ }^{57}$ and phenix.refine. ${ }^{58}$ The restraint dictionary for gepotidacin was made with Acedrg. ${ }^{59}$ The $2.37 \AA$ gepotidacin crystal with the gyrase core fusion truncate and the intact 20-444T DNA was in a different cell from previously reported NBTI crystal structures. This $2.37 \AA$ structure was solved by molecular replacement using the domain from $2 x c s$ and refined with refmac. ${ }^{59}$ The crystallographic details for both structures are given in Table $\mathrm{S} 1$.

The deposited crystallographic coordinates, each of which represents the millions of complexes in the crystal, contain two 'equivalent' orientations of the compound, related by $\mathrm{C} 2$ symmetry. In any one complex there will only be one compound bound, and single biological complexes with one compound can be readily derived from the crystal structures. Biologically relevant complexes with NBTIs are now available at https://www.cardiff.ac.uk/ people/view/1141625-bax-benjamin (Click on Research tab). Note that NBTIs bind in two pockets on the twofold axis of the complex, which are named 2므 (pocket in DNA), and pocket $2 \underline{\mathrm{A}}$ (pocket between the two Gyr $\underline{\mathrm{A}}$ subunits). NBTI complexes use a nomenclature which is non-conventional by PDB standards, because the structures are of a fusion protein in which residues from the C-terminal region of $S$. aureus GyrB (409-644) have been fused to amino-acids from the N-terminus of GyrA (2-491). In our standard 'BA-x' nomenlature the residues in the first GyrBA fusion have CHAINID B if they are from GyrB and CHAINID A, if they are from GyrA. This nomenclature is extended to inhibitors which are given CHAINID I - for inhibitor. NBTIs are given the residue number 2 (i.e., I2), for the 'second' inhibitor site on the twofold axis (the first site which stabilizes cleavage complexes is the cleavage site, occupied by inhibitors such as fluoroquinolones). 
In structural figures that were created using Pymol ${ }^{60}$, carbon atoms in the DNA are green, those in the first GyrBA core fusion truncate subunit are cyan/blue in GyrA and magenta in GyrB, and those in the second subunit are grey or black. Carbon atoms in NBTIs are yellow or orange, and oxygen, nitrogen, and sulfur atoms are red, blue, and yellow, respectively. Water molecules are shown as small red spheres.

\section{RESULTS AND DISCUSSION}

\section{Inhibition of Gyrase Catalytic Activity by Gepotidacin.}

Gyrase has two primary functions in the bacterial cell. First, it generates negative supercoils in DNA and works in conjunction with topoisomerase I to establish and maintain the superhelical density of the bacterial chromosome. Second, it is responsible for removing the positive supercoils that accumulate ahead of replication forks and transcription complexes. 8-9, 11-14, 16 NBTIs were first reported by Coates et al. as a novel class of antibacterials ${ }^{61}$ and subsequently were described as a class of compounds that inhibited the DNA supercoiling reaction of gyrase. ${ }^{7,25,36-38,62}$ Therefore, because of the two critical activities of gyrase in the bacterial cell, the effects of gepotidacin on enzyme-catalyzed DNA supercoiling and relaxation of positively supercoiled DNA were investigated.

As a prelude to the inhibition experiments, $S$. aureus gyrase activity was assessed in the absence of gepotidacin. Starting with positively supercoiled DNA, we followed the time course for the enzyme to remove the positive supercoils and then convert the relaxed DNA to a negatively supercoiled plasmid. As reported previously for gyrase from Bacillus anthracis, Escherichia coli, and Mycobacterium tuberculosis, ${ }^{63-64}$ the $S$. aureus enzyme removed positive supercoils more rapidly than it introduced negative supercoils into relaxed DNA (Figure 2). Whereas all of the positive supercoils were gone within $60 \mathrm{~s}$, it took $\sim 20 \mathrm{~min}$ to convert the plasmid into fully negatively supercoiled DNA. This $\sim 20$-fold time difference between the two reactions likely reflects the acute temporal requirement to rapidly remove positive supercoils that accumulate in front of the replication fork as compared to the maintenance of steady state levels of negative DNA supercoiling. ${ }^{63-64}$

As seen in Figure 3, gepotidacin was a potent inhibitor of gyrase activity. The $\mathrm{IC}_{50}$ for inhibition of DNA supercoiling (top left panel) was $\sim 0.047 \mu \mathrm{M}$ and that for the relaxation of positive DNA supercoils (top right panel) was $\sim 0.6 \mu \mathrm{M}$. In contrast, the $\mathrm{IC}_{50}$ values for the inhibition of supercoiling and relaxation by moxifloxacin, a clinically relevant fluoroquinolone were $\sim 11.5 \mu \mathrm{M}$ (bottom left panel) and $\sim 73 \mu \mathrm{M}$ (bottom right panel), respectively. Thus, gepotidacin is considerably more potent ( 240- and 120-fold, respectively) than moxifloxacin in its ability to inhibit the two critical catalytic functions of S. aureus gyrase.

\section{Enhancement of Gyrase-mediated DNA Cleavage by Gepotidacin.}

Because some NBTIs induce DNA scission by bacterial type II topoisomerases, $7-8,24-25,38,44$ we examined the effects of gepotidacin on the ability of $S$. aureus gyrase to cleave DNA (Figure 4). In contrast to fluoroquinolones, which generate primarily doublestranded DNA breaks, all of the breaks created in the presence of gepotidacin were single- 
stranded. Furthermore, when gyrase was left out of reaction mixtures, no DNA cleavage was observed even at $200 \mu \mathrm{M}$ gepotidacin and incubation times $(3 \mathrm{~h})$ that were 6 times longer than normally used.

Initial experiments to further characterize the induction of gyrase-mediated DNA cleavage by gepotidacin utilized negatively supercoiled plasmid (Figure 5, left panel, blue). Gepotidacin strongly enhanced gyrase-mediated DNA cleavage in the nanomolar range $\left[\mathrm{EC}_{50}\right.$ (concentration required to induce $50 \%$ maximal DNA cleavage) $\left.\approx 0.13 \mu \mathrm{M}\right]$ and generated single-stranded DNA breaks in more than $30 \%$ of the initial substrate at low micromolar concentrations. Moreover, gepotidacin was considerably more potent than moxifloxacin, which required micromolar levels to induce substantial levels of doublestranded DNA cleavage ( $\mathrm{EC}_{50} \approx 2 \mu \mathrm{M}$ ) (Figure 5, right panel, black).

Because drug-stabilized cleavage complexes formed on positively supercoiled DNA ahead of replication forks and transcription complexes are most likely to be converted into permanent strand breaks, ${ }^{7-8,24}$ we also examined the effects of gepotidacin on gyrasemediated cleavage of positively supercoiled DNA (Figure 5, left panel, red). As reported for other species of gyrase with fluoroquinolones and NBTI-like compounds, ${ }^{31,44,63-64}$ gepotidacin induced $\sim 2$-fold lower levels of single-stranded breaks in the presence of the $S$. aureus enzyme and positively supercoiled as compared to negatively supercoiled plasmid. In addition, the potency of gepotidacin with positively supercoiled DNA was slightly higher than that seen with negatively supercoiled substrate $\left(\mathrm{EC}_{50} \approx 0.18 \mu \mathrm{M}\right)$. As with negatively supercoiled plasmid, no double-stranded breaks were observed.

In contrast to the results with the NBTI, the efficacy of moxifloxacin-induced doublestranded breaks in positively supercoiled plasmid (Figure 5, right panel, green) was similar to that seen with negatively supercoiled DNA. However, the potency of the drug fell $\sim 8$-fold with positively supercoiled substrates $\left(\mathrm{EC}_{50} \approx 17\right.$ or $2 \mu \mathrm{M}$ with positively or negatively supercoiled DNA, respectively). As above, gepotidacin was considerably ( 10- to 100-fold) more potent against $S$. aureus gyrase than moxifloxacin.

Some topoisomerase II-targeted drugs, such as the anticancer drug etoposide, induce predominantly single-stranded breaks at low concentrations with either eukaryotic or prokaryotic type II topoisomerases; however, double-stranded breaks become more prevalent at increasing drug concentrations. ${ }^{65-67}$ It is assumed that this change from single- to doublestranded DNA cleavage reflects a decreased affinity for the binding of the second drug molecule. Thus, to determine whether gepotidacin displays a similar ability to induce gyrase-mediated double-stranded breaks at high concentrations, DNA cleavage assays were carried out in the presence of $200 \mu \mathrm{M}$ compound, which is $\sim 40$ times the concentration needed to induce maximal levels of single-stranded DNA breaks (Figure 6). The DNA cleavage profile for $200 \mu \mathrm{M}$ gepotidacin was identical to that observed for $5 \mu \mathrm{M}$ compound, even over a time course that was 6 times longer than used under standard conditions (Figure 6). As seen at lower drug concentrations, only single-stranded breaks were observed.

Although gyrase does not require ATP in order to cleave DNA, the high energy cofactor is necessary for DNA strand passage and enzyme turnover. ${ }^{2,5}$ The DNA cleavage assays 
shown in earlier figures did not include ATP in reaction mixtures. Therefore, the effects of gepotidacin on gyrase-mediated DNA cleavage were carried out in the presence of $1.5 \mathrm{mM}$ ATP to determine whether the high-energy cofactor affects the ability of the compound to generate single- vs. double-stranded DNA breaks (Figure 7). Whereas the compound is more potent in the presence of $\mathrm{ATP}\left(\mathrm{EC}_{50} \approx 0.04 \mu \mathrm{M}\right.$ as compared to $\mathrm{EC}_{50} \approx 0.13 \mu \mathrm{M}$ in the absence of ATP), no double-stranded DNA cleavage was observed.

Taken together the above data lead to the conclusion that gepotidacin induces only singlestranded DNA breaks mediated by $S$. aureus gyrase.

\section{Gepotidacin Induces Stable Gyrase-DNA Cleavage Complexes.}

In general, the ability of topoisomerase-targeted drugs to kill cells correlates with the stability of cleavage complexes formed in their presence. ${ }^{68}$ Therefore, we examined the stability of $S$. aureus gyrase-DNA cleavage complexes that were generated in gepotidacincontaining reactions. This was accomplished by monitoring the decay in DNA scission following a 20-fold dilution of reaction mixtures into a buffer that lacked the divalent metal ion required for cleavage. This assay is believed to reflect the rate at which the ternary gyrase-DNA-drug complex dissociates, given that these complexes are unlikely to re-form in a diluted reaction mixture that lacks substantial levels of divalent metal ion. As seen in Figure 8, gyrase-DNA cleavage complexes formed in the presence of gepotidacin were highly stable and displayed little dissociation even $4 \mathrm{~h}$ after dilution. The stability of these single-stranded DNA cleavage complexes appeared to be similar to or marginally greater than that of the doubly cleaved counterparts generated in the presence of moxifloxacin. In contrast, in the absence of the NBTI or fluoroquinolone the lifetime of single- or doublestranded DNA cleavage complexes formed by $S$. aureus gyrase following dilution was $<10 \mathrm{~s}$.

\section{Gepotidacin Suppresses Gyrase-Mediated Double-Stranded DNA Cleavage.}

Cleavage of the two strands of the double helix by type II topoisomerases are coordinated but individual events (i.e., cleavage at one scissile bond does not necessarily affect cleavage at the other). ${ }^{65}$ Thus, the single-stranded DNA cleavage that occurs in the presence of gepotidacin can reflect two possible mechanisms. Either the compound induces cleavage at only one of the two scissile bonds in any cleavage complex or the cleavage of one scissile bond in the presence of gepotidacin alters the enzyme-DNA complex such that the second DNA strand cannot be cut. This latter mechanism is supported by a structural model that suggests that the second strand is only cleaved when $S$. aureus gyrase adopts an asymmetric conformation after the first strand has been cleaved. ${ }^{65-67}$ NBTIs are believed to block the transformation to the asymmetric conformation, thus preventing cleavage of the second strand. ${ }^{65-67}$ This mechanism is consistent with the single-stranded DNA cleavage induced by Mycobacterium tuberculosis gyrase inhibitors (MGIs), which constitute a subclass of NBTIs optimized for activity against $M$. tuberculosis gyrase. ${ }^{44}$

Unfortunately, the low baseline level of double-stranded DNA cleavage mediated by $S$. aureus gyrase makes it difficult to distinguish between these two possibilities. To overcome this difficulty, we substituted the $\mathrm{MgCl}_{2}$ in DNA cleavage assays with $\mathrm{CaCl}_{2}$ (Figure 9). Although the fundamental properties of DNA cleavage and ligation are not altered by this 
substitution, ${ }^{51-52}$ baseline levels of enzyme-mediated double-stranded DNA cleavage in the presence of $\mathrm{Ca}^{2+}(\sim 15 \%)$ are substantially higher as compared to those observed in $\mathrm{Mg}^{2+}$ containing reactions $(<1 \%)$. As seen in Figure 9, the rise in single-stranded DNA cleavage induced by increasing concentrations of gepotidacin was accompanied by a coordinate decrease in levels of double-stranded DNA cleavage. This result provides strong evidence that cleavage of one scissile bond in the presence of gepotidacin suppresses the ability of $S$. aureus gyrase to cleave the scissile bond on the opposite strand.

\section{Gepotidacin Can Displace Moxifloxacin from the Active Site of S. aureus Gyrase.}

Previous structural studies with NBTIs indicate that they bind to bacterial type II topoisomerases at the DNA cleavage active site and interact with the DNA between the two scissile bonds. ${ }^{25,}{ }^{54-55}$ Although their site of interaction within the enzyme-DNA complex is not identical to those of fluoroquinolones (which interact at the two cleaved scissile bonds), a modeling study suggested that moxifloxacin and the MGI GSK000 and moxifloxacin could not coexist in a cleavage complex formed by M. tuberculosis gyrase. ${ }^{44}$ Therefore, a cleavage competition assay was carried out to determine whether gepotidacin and moxifloxacin could occupy the same cleavage complex established with $S$. aureus gyrase. In this assay, cleavage complexes were formed in the presence of a mixture of $25 \mu \mathrm{M}$ moxifloxacin and increasing concentrations of gepotidacin $(0-100 \mu \mathrm{M})$. Competition was monitored by the loss of double-stranded DNA breaks, which could have been induced only by moxifloxacin. As seen in Figure 10, levels of double-stranded breaks dropped 95\% in the presence of $100 \mu \mathrm{M}$ gepotidacin, which indicates that the binding of the NBTI and moxifloxacin in the active site of the $S$. aureus gyrase-DNA cleavage complex are mutually exclusive.

\section{Structure of the S. aureus gyrase-DNA-Gepotidacin Ternary Complex.}

Given the results of the competition studies and the fact that previous NBTIs have been localized to the DNA cleavage active site of bacterial type II topoisomerases, we further examined gepotidacin interactions within the enzyme-DNA complex. To this end, two crystal structures of gepotidacin with the $S$. aureus core fusion truncate were determined (Tables S1, S2). A schematic of the truncate is shown in Figure S1. The first structure ( $2.31 \AA$ resolution) included a truncate that contained a GyrA ${ }^{\mathrm{Y} 123 \mathrm{~F}}$ mutation and a doubly nicked 20 base pair DNA duplex (Figure 11 and Figure S2, which contains an animation). Because the binding pocket for gepotidacin is on the twofold axis of the complex, the electron density observed is an average of two equivalent binding modes for the compound related by the $\mathrm{C} 2$ axis of the complex. The second structure ( $2.37 \AA$ resolution) included a wild-type gyrase truncate and an intact (uncleaved) 20 base pair DNA substrate (Figure 12).

The binding mode we observed for gepotidacin is similar to that reported previously for other NBTIs, including GSK945237 (Figure S3) ${ }^{25,54-55}$ In contrast to fluoroquinolones, which bind in the DNA at the two four base-pair separated cleavage sites, ${ }^{25,} 30,32-33$ only a single molecule of gepotidacin binds in the $S$. aureus gyrase-DNA complex.

The left-hand side (triazaacenaphthylene) of gepotidacin sits in a pocket in the DNA on the twofold axis of the complex (pocket 2D), midway between the two DNA cleavage sites, and 
the right-hand side (pyranopyridine) sits in a pocket on the twofold axis between the two GyrA subunits (pocket 2A; Figures 11 and 12). Pocket 2A does not exist in the apo structure ${ }^{25}$ or in a binary complex of uncleaved DNA with $S$. aureus DNA gyrase. ${ }^{69} \mathrm{It}$ is notable that there is a relative movement of the two GyrA subunits of about $1.2 \AA$ in the two gepotidacin crystal structures. As a result, when the two structures are aligned on the basis of the GyrA subunits, the right-hand side and left-hand side of gepotidacin are not in identical positions (Figure 12). This finding strongly suggests that there is flexibility about the central linker of gepotidacin. The flexibility may allow the compound to remain stably bound to multiple different enzyme-DNA complexes, including those that contain intact or nicked DNA substrates. This attribute may explain how some NBTIs inhibit gyrase activity without enhancing cleavage, while others are able to do both. $7,25,36-42$

\section{CONCLUSIONS}

Due to the rise in antibacterial drug resistance, there is a critical need for the development of new agents that retain activity against resistant infections. One approach, which led to the development of the NBTIs, is to identify compounds that work against validated clinical targets, such as the bacterial type II topoisomerases, gyrase and topoisomerase IV, and retain activity against fluoroquinolone-resistant enzymes. Although gepotidacin and other NBTIs bind in the same DNA cleavage active site of gyrase as fluoroquinolones, they display distinct interactions. Whereas, fluoroquinolones interact with $S$. aureus gyrase through water-mediated contacts with Ser84 and Glu88 in the GyrA subunit, the basic nitrogen of gepotidacin interacts directly with GyrA Asp83 from one subunit, and indirectly via a water molecule with Asp83 from the second GyrA subunit. ${ }^{25-31}$ Hence, NBTIs and related compounds are able to retain activity against the most common gyrase mutations that are resistant to clinically relevant fluoroquinolones.

Gepotidacin is a first-in-class triazaacenaphthylene NBTI. Despite its success in clinical trials against skin/skin structure infections (such as those caused by $S$. aureus) and uncomplicated urogenital gonorrhea, ${ }^{45-47}$ nothing had been reported about its interactions with its bacterial type II topoisomerase targets. Therefore, the current work characterized the activity of the compound against $S$. aureus gyrase. Gepotidacin was a potent inhibitor of gyrase activity and enhanced enzyme-mediated DNA cleavage. In contrast to fluoroquinolones, the compound enhanced only single-stranded DNA breaks. Further studies will be required to determine whether our proposed model for how gepotidacin blocks gyrase-mediated cleavage of the second strand is correct. However, as discussed above, we propose that the compound prevents the enzyme from attaining the asymmetric conformation that is necessary to promote cleavage at the second strand. Finally, it will be interesting to determine how the stimulation of enzyme-mediated DNA cleavage and the inhibition of type II topoisomerases ultimately contribute to bacterial cell death following treatment with gepotidacin.

\section{Supplementary Material}

Refer to Web version on PubMed Central for supplementary material. 


\title{
ACKNOWLEDGEMENTS
}

\author{
We are grateful to Lorena Infante Lara, Alexandria A. Oviatt, and Esha D. Dalvie for critical reading of the \\ manuscript. We thank Onkar Singh and Velupillai Srikannathasan for help with crystallization. \\ Funding \\ This work was supported by the US Veterans Administration (Merit Review award I01 Bx002198 to N.O.) and the \\ National Institutes of Health (R01 GM126363 to N.O.). E.G.G was supported by a Pharmacology Training Grant \\ (5T32GM007628) from the National Institutes of Health and pre-doctoral fellowships from the PhRMA Foundation \\ and the American Association of Pharmaceutical Scientists.
}

\section{REFERENCES}

1. Hooper DC (1999) Mechanisms of fluoroquinolone resistance. Drug Resist. Updat 2 (1), 38-55. DOI: 10.1054/drup.1998.0068. [PubMed: 11504468]

2. Anderson VE, Osheroff N (2001) Type II topoisomerases as targets for quinolone antibacterials: turning Dr. Jekyll into Mr. Hyde. Curr. Pharm. Des 7 (5), 337-353. DOI: 10.2174/1381612013398013 [PubMed: 11254893]

3. Drlica K, Hiasa H, Kerns R, Malik M, Mustaev A, Zhao X (2009) Quinolones: action and resistance updated. Curr. Top. Med. Chem 9 (11), 981-998. DOI: 10.2174/156802609789630947. [PubMed: 19747119]

4. Chen SH, Chan NL, Hsieh TS (2013) New mechanistic and functional insights into DNA topoisomerases. Annu. Rev. Biochem 82, 139-170. DOI: 10.1146/annurevbiochem-061809-100002. [PubMed: 23495937]

5. Aldred KJ, Kerns RJ, Osheroff N (2014) Mechanism of quinolone action and resistance. Biochemistry. 53 (10), 1565-1574. DOI: 10.1021/bi5000564. [PubMed: 24576155]

6. Hooper DC, Jacoby GA (2015) Mechanisms of drug resistance: quinolone resistance. Ann. NY Acad. Sci 1354, 12-31. DOI: 10.1111/nyas.12830. [PubMed: 26190223]

7. Gibson EG, Ashley RE, Kerns RJ, Osheroff N, Fluoroquinolone interactions with bacterial type II topoisomerases and target-mediated drug resistance In Antimicrobial Resistance and Implications for the 21st Century, Drlica K; Shlaes D; Fong IW, Eds. Springer: 2018; pp 507-529.

8. Levine C, Hiasa H, Marians KJ (1998) DNA gyrase and topoisomerase IV: biochemical activities, physiological roles during chromosome replication, and drug sensitivities. Biochim. Biophys. Acta 1400 (1-3), 29-43. DOI: 10.1016/S0167-4781(98)00126-2. [PubMed: 9748489]

9. Sissi C, Palumbo M (2010) In front of and behind the replication fork: bacterial type IIA topoisomerases. Cell. Mol. Life Sci 67 (12), 2001-2024. DOI: 10.1007/s00018-010-0299-5. [PubMed: 20165898]

10. Bush NG, Evans-Roberts K, Maxwell A (2015) DNA topoisomerases. EcoSal Plus. 6 (2). DOI: 10.1128/ecosalplus.ESP-0010-2014.

11. Willmott CJ, Critchlow SE, Eperon IC, Maxwell A (1994) The complex of DNA gyrase and quinolone drugs with DNA forms a barrier to transcription by RNA polymerase. J. Mol. Biol 242 (4), 351-363. DOI: 10.1006/jmbi.1994.1586. [PubMed: 7932695]

12. Khodursky AB, Peter BJ, Schmidt MB, DeRisi J, Botstein D, Brown PO, Cozzarelli NR (2000) Analysis of topoisomerase function in bacterial replication fork movement: Use of DNA microarrays. P. Natl. Acad. Sci. USA 97 (17), 9419-9424. DOI: DOI 10.1073/pnas.97.17.9419.

13. Tadesse S, Graumann PL (2006) Differential and dynamic localization of topoisomerases in Bacillus subtilis. J. Bacteriol 188 (8), 3002-3011. DOI: 10.1128/JB.188.8.3002-3011.2006. [PubMed: 16585761]

14. Hsu YH, Chung MW, Li TK (2006) Distribution of gyrase and topoisomerase IV on bacterial nucleoid: implications for nucleoid organization. Nucleic Acids Res. 34 (10), 3128-3138. DOI: 10.1093/nar/gkl392. [PubMed: 16757578]

15. Rovinskiy N, Agbleke AA, Chesnokova O, Pang Z, Higgins NP (2012) Rates of gyrase supercoiling and transcription elongation control supercoil density in a bacterial chromosome. PLoS Genet. 8 (8), e1002845 DOI: 10.1371/journal.pgen.1002845. [PubMed: 22916023] 
16. Ahmed W, Sala C, Hegde SR, Jha RK, Cole ST, Nagaraja V (2017) Transcription facilitated genome-wide recruitment of topoisomerase I and DNA gyrase. PLoS Genet. 13 (5), e1006754 DOI: 10.1371/journal.pgen.1006754. [PubMed: 28463980]

17. Hiasa H, Marians KJ (1994) Topoisomerase IV can support oriCDNA replication in vitro. J. Biol. Chem 269 (23), 16371-16375. [PubMed: 8206945]

18. Zechiedrich EL, Khodursky AB, Bachellier S, Schneider R, Chen D, Lilley DM, Cozzarelli NR (2000) Roles of topoisomerases in maintaining steady-state DNA supercoiling in Escherichia coli. J. Biol. Chem 275 (11), 8103-8113. DOI: 10.1074/jbc.275.11.8103. [PubMed: 10713132]

19. Crisona NJ, Strick TR, Bensimon D, Croquette V, Cozzarelli NR (2000) Preferential relaxation of positively supercoiled DNA by $E$. coli topoisomerase IV in single-molecule and ensemble measurements. Genes Dev. 14 (22), 2881-2892. DOI: 10.1101/gad.838900. [PubMed: 11090135]

20. Wang X, Reyes-Lamothe R, Sherratt DJ (2008) Modulation of Escherichia coli sister chromosome cohesion by topoisomerase IV. Genes Dev. 22 (17), 2426-2433. DOI: 10.1101/gad.487508. [PubMed: 18765793]

21. Liu Z, Deibler RW, Chan HS, Zechiedrich L (2009) The why and how of DNA unlinking. Nucleic Acids Res. 37 (3), 661-671. DOI: 10.1093/nar/gkp041. [PubMed: 19240147]

22. Zawadzki P, Stracy M, Ginda K, Zawadzka K, Lesterlin C, Kapanidis AN, Sherratt DJ (2015) The localization and action of topoisomerase IV in Escherichia coli chromosome segregation is coordinated by the SMC complex, MukBEF. Cell Rep. 13 (11), 2587-2596. DOI: 10.1016/j.celrep. 2015.11.034. [PubMed: 26686641]

23. Vos SM, Tretter EM, Schmidt BH, Berger JM (2011) All tangled up: how cells direct, manage and exploit topoisomerase function. Nat. Rev. Mol. Cell Biol 12 (12), 827-841. DOI: 10.1038/ nrm3228. [PubMed: 22108601]

24. Deweese JE, Osheroff N (2009) The DNA cleavage reaction of topoisomerase II: wolf in sheep's clothing. Nucleic Acids Res. 37 (3), 738-748. DOI: 10.1093/nar/gkn937. [PubMed: 19042970]

25. Bax BD, Chan PF, Eggleston DS, Fosberry A, Gentry DR, Gorrec F, Giordano I, Hann MM, Hennessy A, Hibbs M, Huang J, Jones E, Jones J, Brown KK, Lewis CJ, May EW, Saunders MR, Singh O, Spitzfaden CE, Shen C, Shillings A, Theobald AJ, Wohlkonig A, Pearson ND, Gwynn MN (2010) Type IIA topoisomerase inhibition by a new class of antibacterial agents. Nature. 466 (7309), 935-940. DOI: 10.1038/nature09197. [PubMed: 20686482]

26. Aldred KJ, McPherson SA, Wang P, Kerns RJ, Graves DE, Turnbough CL Jr., Osheroff N (2012) Drug interactions with Bacillus anthracis topoisomerase IV: biochemical basis for quinolone action and resistance. Biochemistry. 51 (1), 370-381. DOI: 10.1021/bi2013905. [PubMed: 22126453]

27. Aldred KJ, Breland EJ, Vlčková V, Strub MP, Neuman KC, Kerns RJ, Osheroff N (2014) Role of the water-metal ion bridge in mediating interactions between quinolones and Escherichia coli topoisomerase IV. Biochemistry. 53 (34), 5558-5567. DOI: 10.1021/bi500682e. [PubMed: 25115926]

28. Aldred KJ, McPherson SA, Turnbough CL Jr., Kerns RJ, Osheroff N (2013) Topoisomerase IVquinolone interactions are mediated through a water-metal ion bridge: mechanistic basis of quinolone resistance. Nucleic Acids Res. 41 (8), 4628-4639. DOI: 10.1093/nar/gkt124. [PubMed: 23460203]

29. Aldred KJ, Schwanz HA, Li G, McPherson SA, Turnbough CL Jr., Kerns RJ, Osheroff N (2013) Overcoming target-mediated quinolone resistance in topoisomerase IV by introducing metal-ionindependent drug-enzyme interactions. ACS Chem. Biol 8 (12), 2660-2668. DOI: 10.1021/ cb400592n. [PubMed: 24047414]

30. Blower TR, Williamson BH, Kerns RJ, Berger JM (2016) Crystal structure and stability of gyrasefluoroquinolone cleaved complexes from Mycobacterium tuberculosis. Proc. Natl. Acad. Sci. USA 113 (7), 1706-1713. DOI: 10.1073/pnas.1525047113. [PubMed: 26792525]

31. Ashley RE, Lindsey RH Jr., McPherson SA, Turnbough CL Jr., Kerns RJ, Osheroff N (2017) Interactions between quinolones and Bacillus anthracis gyrase and the basis of drug resistance. Biochemistry. 56 (32), 4191-4200. DOI: 10.1021/acs.biochem.7b00203. [PubMed: 28708938]

32. Laponogov I, Sohi MK, Veselkov DA, Pan XS, Sawhney R, Thompson AW, McAuley KE, Fisher LM, Sanderson MR (2009) Structural insight into the quinolone-DNA cleavage complex of type 
IIA topoisomerases. Nat. Struct. Mol. Biol 16 (6), 667-669. DOI: 10.1038/nsmb.1604. [PubMed: 19448616]

33. Laponogov I, Pan XS, Veselkov DA, Cirz RT, Wagman A, Moser HE, Fisher LM, Sanderson MR (2016) Exploring the active site of the Streptococcus pneumoniae topoisomerase IV-DNA cleavage complex with novel 7,8-bridged fluoroquinolones. Open Biol. 6 (9). DOI: 10.1098/rsob.160157.

34. Pommier Y, Leo E, Zhang H, Marchand C (2010) DNA topoisomerases and their poisoning by anticancer and antibacterial drugs. Chem. Biol 17 (5), 421-433. DOI: 10.1016/j.chembiol. 2010.04.012. [PubMed: 20534341]

35. Hooper DC (1999) Mode of action of fluoroquinolones. Drugs. 58 Suppl 2, 6-10. DOI: 10.2165/00003495-199958002-00002. [PubMed: 10553698]

36. Dougherty TJ, Nayar A, Newman JV, Hopkins S, Stone GG, Johnstone M, Shapiro AB, Cronin M, Reck F, Ehmann DE (2014) NBTI 5463 is a novel bacterial type II topoisomerase inhibitor with activity against gram-negative bacteria and in vivo efficacy. Antimicrob. Agents Chemother 58 (5), 2657-2664. DOI: 10.1128/AAC.02778-13. [PubMed: 24566174]

37. Charrier C, Salisbury AM, Savage VJ, Duffy T, Moyo E, Chaffer-Malam N, Ooi N, Newman R, Cheung J, Metzger R, McGarry D, Pichowicz M, Sigerson R, Cooper IR, Nelson G, Butler HS, Craighead M, Ratcliffe AJ, Best SA, Stokes NR (2017) Novel bacterial topoisomerase inhibitors with potent broad-spectrum activity against drug-resistant bacteria. Antimicrob. Agents Chemother. 61 (5), e02100-02116. DOI: 10.1128/AAC.02100-16. [PubMed: 28223393]

38. Hiasa H (2018) DNA topoisomerases as targets for antibacterial agents. Methods Mol. Biol 1703, 47-62. DOI: 10.1007/978-1-4939-7459-7_3. [PubMed: 29177732]

39. Black MT, Stachyra T, Platel D, Girard AM, Claudon M, Bruneau JM, Miossec C (2008) Mechanism of action of the antibiotic NXL101, a novel nonfluoroquinolone inhibitor of bacterial type II topoisomerases. Antimicrob. Agents Chemother 52 (9), 3339-3349. DOI: 10.1128/AAC. 00496-08. [PubMed: 18625781]

40. Surivet JP, Zumbrunn C, Rueedi G, Hubschwerlen C, Bur D, Bruyere T, Locher H, Ritz D, Keck W, Seiler P, Kohl C, Gauvin JC, Mirre A, Kaegi V, Dos Santos M, Gaertner M, Delers J, EnderlinPaput M, Boehme M (2013) Design, synthesis, and characterization of novel tetrahydropyranbased bacterial topoisomerase inhibitors with potent anti-gram-positive activity. J. Med. Chem 56 (18), 7396-7415. DOI: 10.1021/jm400963y. [PubMed: 23968485]

41. Singh SB, Kaelin DE, Wu J, Miesel L, Tan CM, Meinke PT, Olsen D, Lagrutta A, Bradley P, Lu J, Patel S, Rickert KW, Smith RF, Soisson S, Wei C, Fukuda H, Kishii R, Takei M, Fukuda Y (2014) Oxabicyclooctane-linked novel bacterial topoisomerase inhibitors as broad spectrum antibacterial agents. ACS Med. Chem. Lett 5 (5), 609-614. DOI: 10.1021/ml500069w. [PubMed: 24900889]

42. Mitton-Fry MJ, Brickner SJ, Hamel JC, Barham R, Brennan L, Casavant JM, Ding X, Finegan S, Hardink J, Hoang T, Huband MD, Maloney M, Marfat A, McCurdy SP, McLeod D, Subramanyam C, Plotkin M, Reilly U, Schafer J, Stone GG, Uccello DP, Wisialowski T, Yoon K, Zaniewski R, Zook C (2017) Novel 3-fluoro-6-methoxyquinoline derivatives as inhibitors of bacterial DNA gyrase and topoisomerase IV. Bioorg. Med. Chem. Lett 27 (15), 3353-3358. DOI: 10.1016/j.bmcl. 2017.06.009. [PubMed: 28610977]

43. Biedenbach DJ, Bouchillon SK, Hackel M, Miller LA, Scangarella-Oman NE, Jakielaszek C, Sahm DF (2016) In vitro activity of gepotidacin, a novel triazaacenaphthylene bacterial topoisomerase inhibitor, against a broad spectrum of bacterial pathogens. Antimicrob. Agents Chemother 60 (3), 1918-1923. DOI: 10.1128/AAC.02820-15. [PubMed: 26729499]

44. Gibson EG, Blower TR, Cacho M, Bax B, Berger JM, Osheroff N (2018) Mechanism of action of Mycobacterium tuberculosis gyrase inhibitors: a novel class of gyrase poisons. ACS Infect. Dis 4 (8), 1211-1222. DOI: 10.1021/acsinfecdis.8b00035. [PubMed: 29746087]

45. Scangarella-Oman NE, Hossain M, Dixon PB, Ingraham K, Min S, Tiffany CA, Perry CR, Raychaudhuri A, Dumont EF, Huang J, Hook EW 3rd, Miller LA (2018) Microbiological analysis from a phase 2 randomized study in adults evaluating single oral doses of gepotidacin in the treatment of uncomplicated urogenital gonorrhea caused by Neisseria gonorrhoeae. Antimicrob. Agents Chemother. [Epub ahead of print]. DOI: 10.1128/AAC.01221-18.

46. Taylor SN, Morris DH, Avery AK, Workowski KA, Batteiger BE, Tiffany CA, Perry CR, Raychaudhuri A, Scangarella-Oman NE, Hossain M, Dumont EF (2018) Gepotidacin for the treatment of uncomplicated urogenital gonorrhea: A phase 2, randomized, dose-ranging, single- 
oral dose evaluation. Clin. Infect. Dis 67 (4), 504-512. DOI: 10.1093/cid/ciy145. [PubMed: 29617982]

47. O'Riordan W, Tiffany C, Scangarella-Oman N, Perry C, Hossain M, Ashton T, Dumont E (2017) Efficacy, safety, and tolerability of gepotidacin (GSK2140944) in the treatment of patients with suspected or confirmed Gram-positive acute bacterial skin and skin structure infections. Antimicrob. Agents Chemother. 61 (6), e02095-02016. DOI: 10.1128/AAC.02095-16. [PubMed: 28373199]

48. WHO. Update on antibacterial agents in clinical development. http://www.who.int/iris/handle/ 10665/275487 (accessed 2018).

49. McClendon AK, Rodriguez AC, Osheroff N (2005) Human topoisomerase IIa rapidly relaxes positively supercoiled DNA: implications for enzyme action ahead of replication forks. J. Biol. Chem 280 (47), 39337-39345. DOI: 10.1074/jbc.M503320200. [PubMed: 16188892]

50. Rodriguez AC (2002) Studies of a positive supercoiling machine. Nucleotide hydrolysis and a multifunctional "latch" in the mechanism of reverse gyrase. J. Biol. Chem 277 (33), 29865-29873. DOI: 10.1074/jbc.M202853200. [PubMed: 12048189]

51. Aldred KJ, Blower TR, Kerns RJ, Berger JM, Osheroff N (2016) Fluoroquinolone interactions with Mycobacterium tuberculosis gyrase: Enhancing drug activity against wild-type and resistant gyrase. Proc. Natl. Acad. Sci. USA 113 (7), E839-846. DOI: 10.1073/pnas.1525055113. [PubMed: 26792518]

52. Osheroff N, Zechiedrich EL (1987) Calcium-promoted DNA cleavage by eukaryotic topoisomerase II: trapping the covalent enzyme-DNA complex in an active form. Biochemistry. 26 (14), 43034309. [PubMed: 2822084]

53. Srikannathasan V, Wohlkonig A, Shillings A, Singh O, Chan PF, Huang J, Gwynn MN, Fosberry AP, Homes P, Hibbs M, Theobald AJ, Spitzfaden C, Bax BD (2015) Crystallization and initial crystallographic analysis of covalent DNA-cleavage complexes of Staphyloccocus aureus DNA gyrase with QPT-1, moxifloxacin and etoposide. Acta Crystallogr. F Struct. Biol. Commun 71 (Pt 10), 1242-1246. DOI: 10.1107/S2053230X15015290. [PubMed: 26457513]

54. Miles TJ, Hennessy AJ, Bax B, Brooks G, Brown BS, Brown P, Cailleau N, Chen D, Dabbs S, Davies DT, Esken JM, Giordano I, Hoover JL, Huang J, Jones GE, Sukmar SK, Spitzfaden C, Markwell RE, Minthorn EA, Rittenhouse S, Gwynn MN, Pearson ND (2013) Novel hydroxyl tricyclics (e.g., GSK966587) as potent inhibitors of bacterial type IIA topoisomerases. Bioorg. Med. Chem. Lett 23 (19), 5437-5441. DOI: 10.1016/j.bmcl.2013.07.013. [PubMed: 23968823]

55. Miles TJ, Hennessy AJ, Bax B, Brooks G, Brown BS, Brown P, Cailleau N, Chen D, Dabbs S, Davies DT, Esken JM, Giordano I, Hoover JL, Jones GE, Kusalakumari Sukmar SK, Markwell RE, Minthorn EA, Rittenhouse S, Gwynn MN, Pearson ND (2016) Novel tricyclics (e.g., GSK945237) as potent inhibitors of bacterial type IIA topoisomerases. Bioorg. Med. Chem. Lett 26 (10), 2464-2469. DOI: 10.1016/j.bmcl.2016.03.106. [PubMed: 27055939]

56. Minor W, Cymborowski M, Otwinowski Z, Chruszcz M (2006) HKL-3000: the integration of data reduction and structure solution-from diffraction images to an initial model in minutes. Acta Crystallogr. D Biol. Crystallogr 62 (Pt 8), 859-866. DOI: 10.1107/S0907444906019949. [PubMed: 16855301]

57. Murshudov GN, Skubak P, Lebedev AA, Pannu NS, Steiner RA, Nicholls RA, Winn MD, Long F, Vagin AA (2011) REFMAC5 for the refinement of macromolecular crystal structures. Acta Crystallogr. D Biol. Crystallogr 67 (Pt 4), 355-367. DOI: 10.1107/S0907444911001314. [PubMed: 21460454]

58. Afonine PV, Grosse-Kunstleve RW, Echols N, Headd JJ, Moriarty NW, Mustyakimov M, Terwilliger TC, Urzhumtsev A, Zwart PH, Adams PD (2012) Towards automated crystallographic structure refinement with phenix.refine. Acta Crystallogr. D Biol. Crystallogr 68 (Pt 4), 352-367. DOI: 10.1107/S0907444912001308. [PubMed: 22505256]

59. Long F, Nicholls RA, Emsley P, Graaeulis S, Merkys A, Vaitkus A, Murshudov GN (2017) AceDRG: a stereochemical description generator for ligands. Acta Crystallogr. D Struct. Biol 73 (Pt 2), 112-122. DOI: 10.1107/S2059798317000067. [PubMed: 28177307]

60. DeLano WL The PyMOL molecular graphics system. http://www.pymol.org.

61. Coates WJ, Gwynn MN, Hatton IK, Masters PJ, Pearson ND, Rahman SS, Slocombe B, and Warrack JD Preparation of piperidinylalkylquinolines as antibacterials. 1999. 
62. Chan PF, Germe T, Bax BD, Huang J, Thalji RK, Bacque E, Checchia A, Chen D, Cui H, Ding X, Ingraham K, McCloskey L, Raha K, Srikannathasan V, Maxwell A, Stavenger RA (2017)

Thiophene antibacterials that allosterically stabilize DNA-cleavage complexes with DNA gyrase. Proc. Natl. Acad. Sci. USA 114 (22), E4492-E4500. DOI: 10.1073/pnas.1700721114. [PubMed: 28507124]

63. Ashley RE, Dittmore A, McPherson SA, Turnbough CL Jr., Neuman KC, Osheroff N (2017) Activities of gyrase and topoisomerase IV on positively supercoiled DNA. Nucleic Acids Res. 45 (16), 9611-9624. DOI: 10.1093/nar/gkx649. [PubMed: 28934496]

64. Ashley RE, Blower TR, Berger JM, Osheroff N (2017) Recognition of DNA supercoil geometry by Mycobacterium tuberculosis gyrase. Biochemistry. 56 (40), 5440-5448. DOI: 10.1021/ acs.biochem.7b00681. [PubMed: 28921956]

65. Bromberg KD, Burgin AB, Osheroff N (2003) A two-drug model for etoposide action against human topoisomerase IIa. J. Biol. Chem 278 (9), 7406-7412. DOI: 10.1074/jbc.M212056200. [PubMed: 12473657]

66. Muslimovic A, Nystrom S, Gao Y, Hammarsten O (2009) Numerical analysis of etoposide induced DNA breaks. PLoS One. 4 (6), e5859 DOI: 10.1371/journal.pone.0005859. [PubMed: 19516899]

67. Chan PF, Srikannathasan V, Huang J, Cui H, Fosberry AP, Gu M, Hann MM, Hibbs M, Homes P, Ingraham K, Pizzollo J, Shen C, Shillings AJ, Spitzfaden CE, Tanner R, Theobald AJ, Stavenger RA, Bax BD, Gwynn MN (2015) Structural basis of DNA gyrase inhibition by antibacterial QPT-1, anticancer drug etoposide and moxifloxacin. Nat. Commun 6, 10048 DOI: 10.1038/ ncomms 10048. [PubMed: 26640131]

68. Bandele OJ, Osheroff N (2008) The efficacy of topoisomerase II-targeted anticancer agents reflects the persistence of drug-induced cleavage complexes in cells. Biochemistry. 47 (45), 11900-11908. DOI: 10.1021/bi800981j. [PubMed: 18922022]

69. Germe T, Voros J, Jeannot F, Taillier T, Stavenger RA, Bacque E, Maxwell A, Bax BD (2018) A new class of antibacterials, the imidazopyrazinones, reveal structural transitions involved in DNA gyrase poisoning and mechanisms of resistance. Nucleic Acids Res. 46 (8), 4114-4128. DOI: 10.1093/nar/gky181. [PubMed: 29538767] 


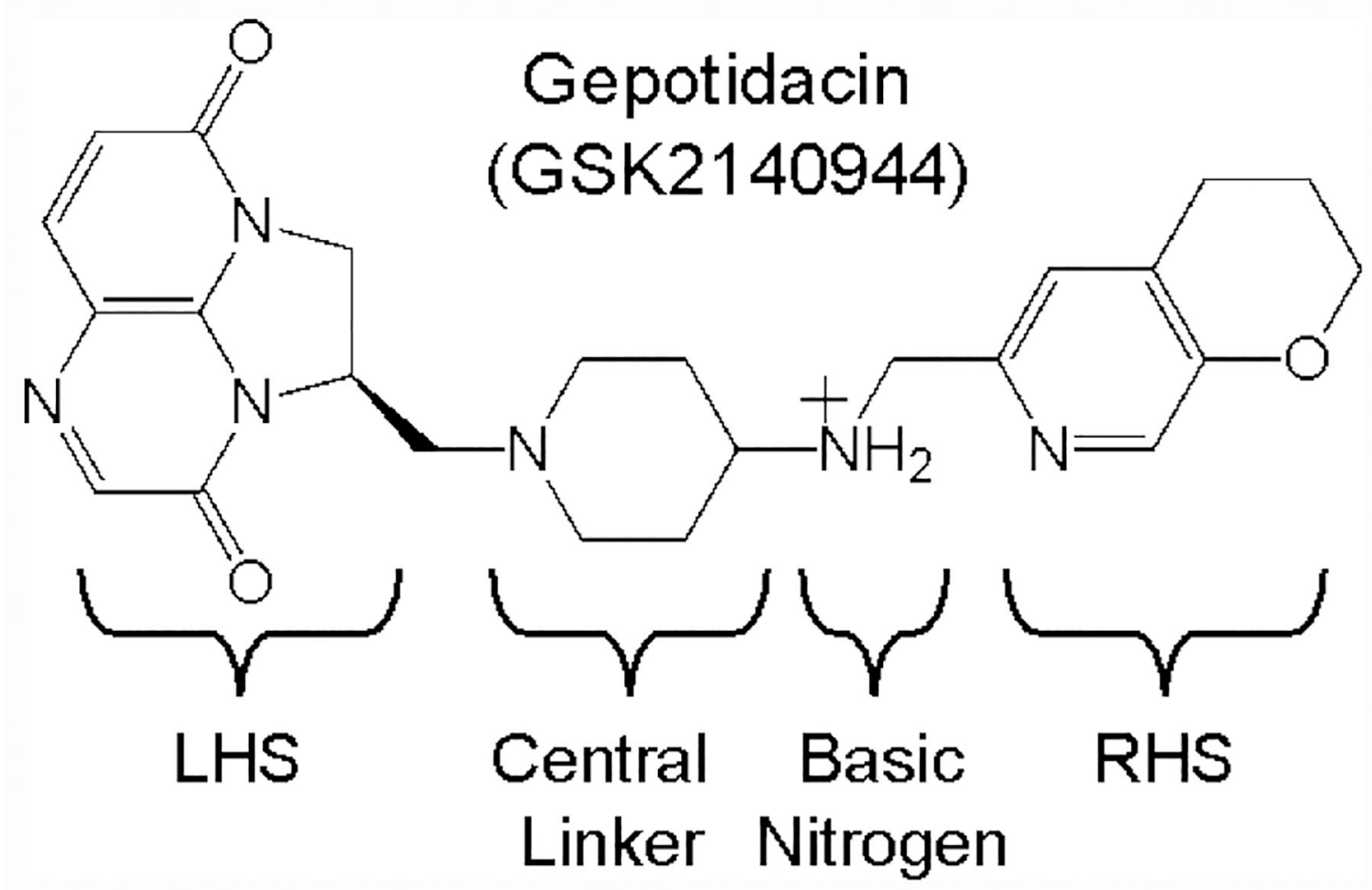

Figure 1:

Structure of the novel bacterial topoisomerase inhibitor (NBTI) gepotidacin (GSK2140944). Gepotidacin is composed of a triazaacenaphthylene on the left-hand side (LHS), a central linker region, a basic nitrogen, and a pyranopyridine on the right-hand side (RHS). 

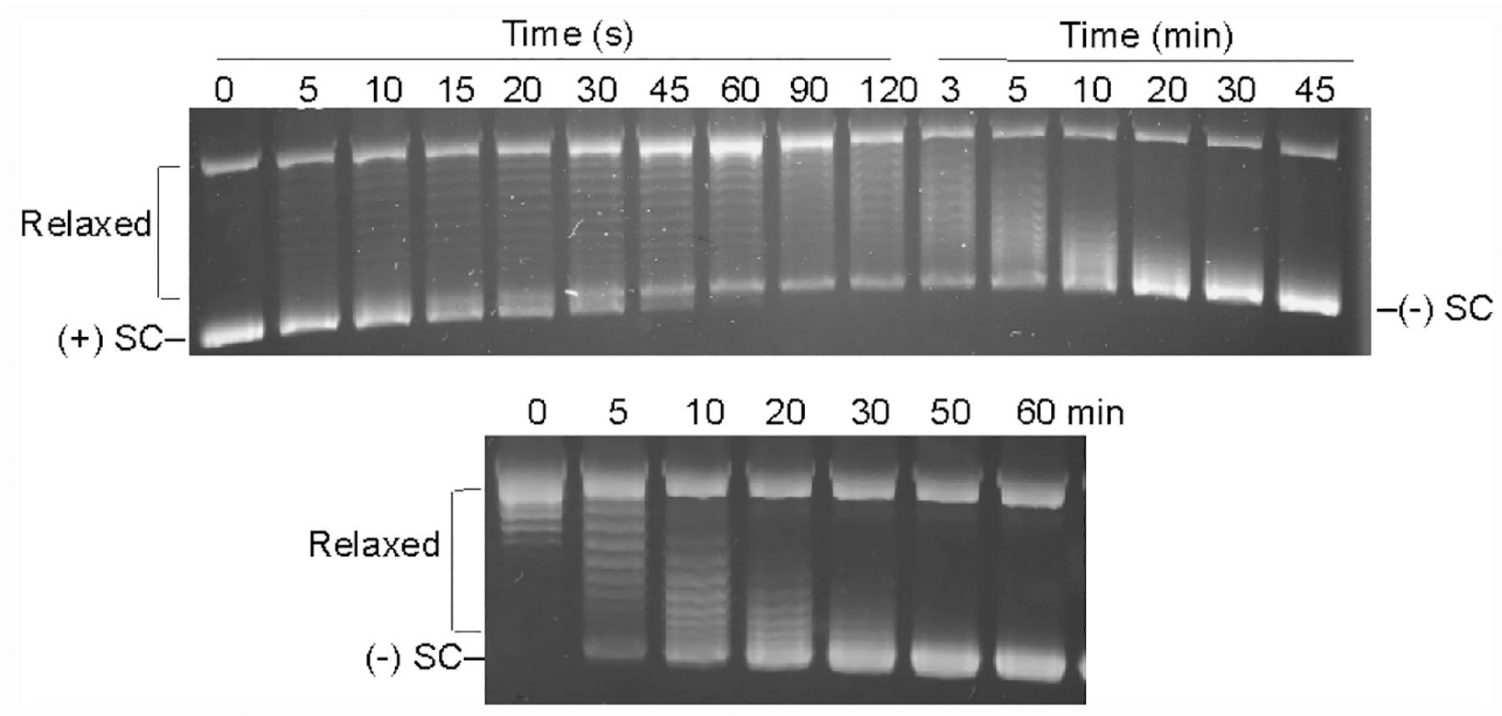

Figure 2:

$S$. aureus gyrase removes positive supercoils more rapidly than it introduces negative supercoils into relaxed DNA. Time courses are shown for the relaxation of positively supercoiled plasmid followed by the introduction of negative supercoils (top) and the negative supercoiling of relaxed plasmid (bottom). The positions of positively supercoiled $[(+) S C]$, relaxed, and negatively supercoiled [(-)SC] DNA are indicated on the gels. The gel images are representative of at least three independent experiments. 

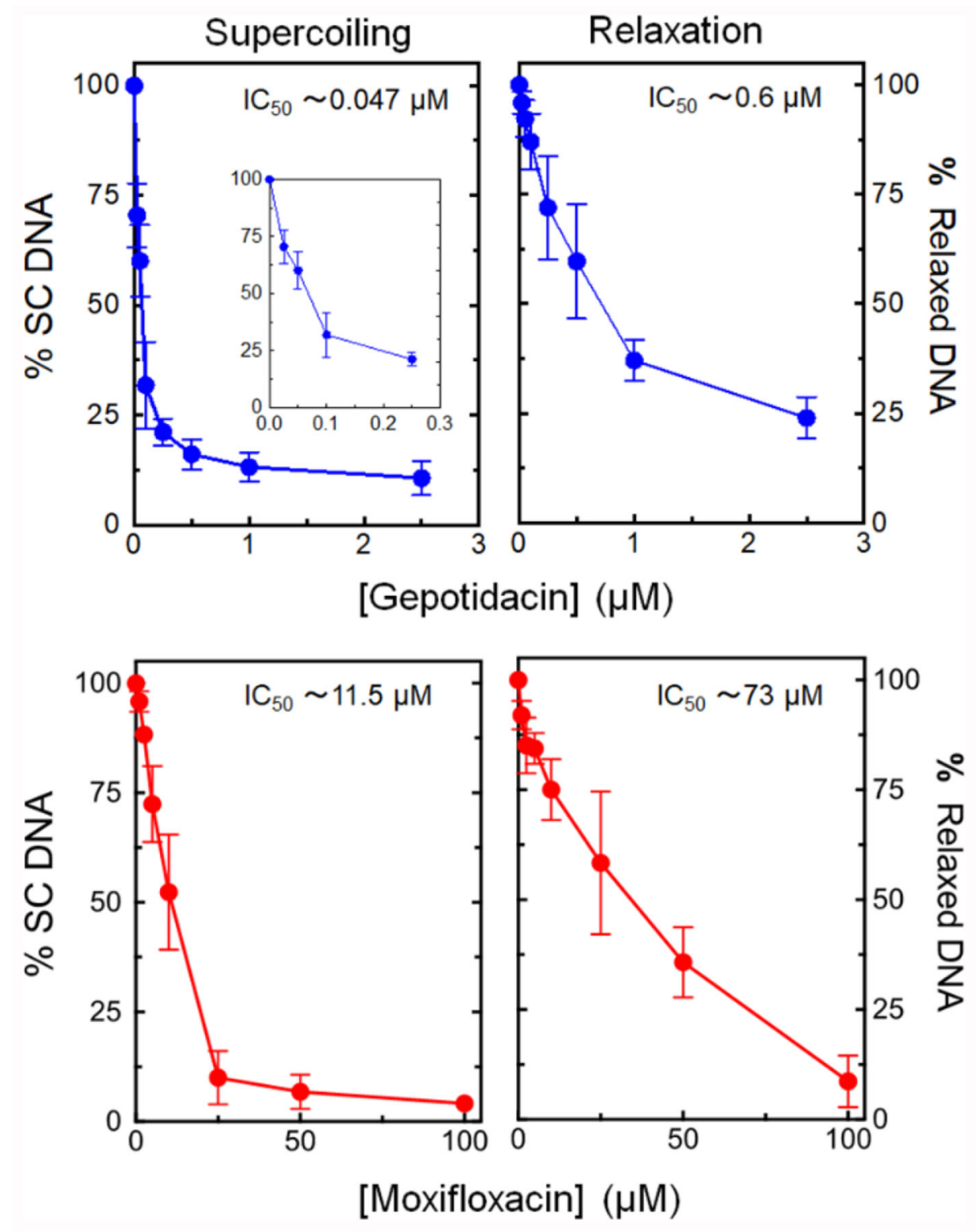

Figure 3:

Gepotidacin and moxifloxacin inhibit DNA supercoiling and relaxation reactions catalyzed by $S$. aureus gyrase. The effects of gepotidacin (blue, top panels) and moxifloxacin (red, bottom panels) on the supercoiling of relaxed DNA (left panels) and the relaxation of positively supercoiled DNA (right panels) are shown. Error bars represent the standard deviation (SD) of at least three independent experiments. 


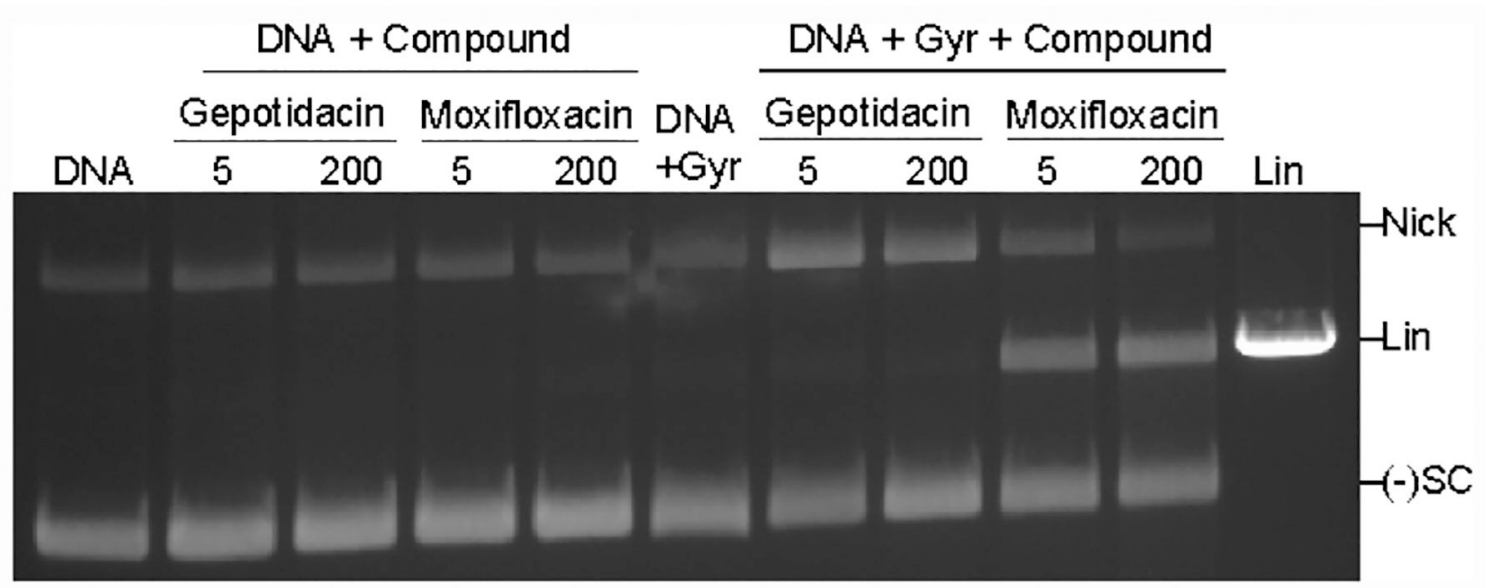

Figure 4:

Gepotidacin induces single-stranded DNA breaks in the presence of gyrase. The gel shows DNA products following cleavage reactions containing 5 or $200 \mu \mathrm{M}$ gepotidacin or moxifloxacin in the absence or presence of $S$. aureus gyrase. The positions of negatively supercoiled [(-)SC], nicked (Nick), and linear (Lin) DNA are indicated on the gels. The generation of single- and double-stranded DNA breaks were monitored by the conversion of negatively supercoiled substrates to nicked and linear DNA products, respectively. The gel images are representative of at least three independent experiments. 


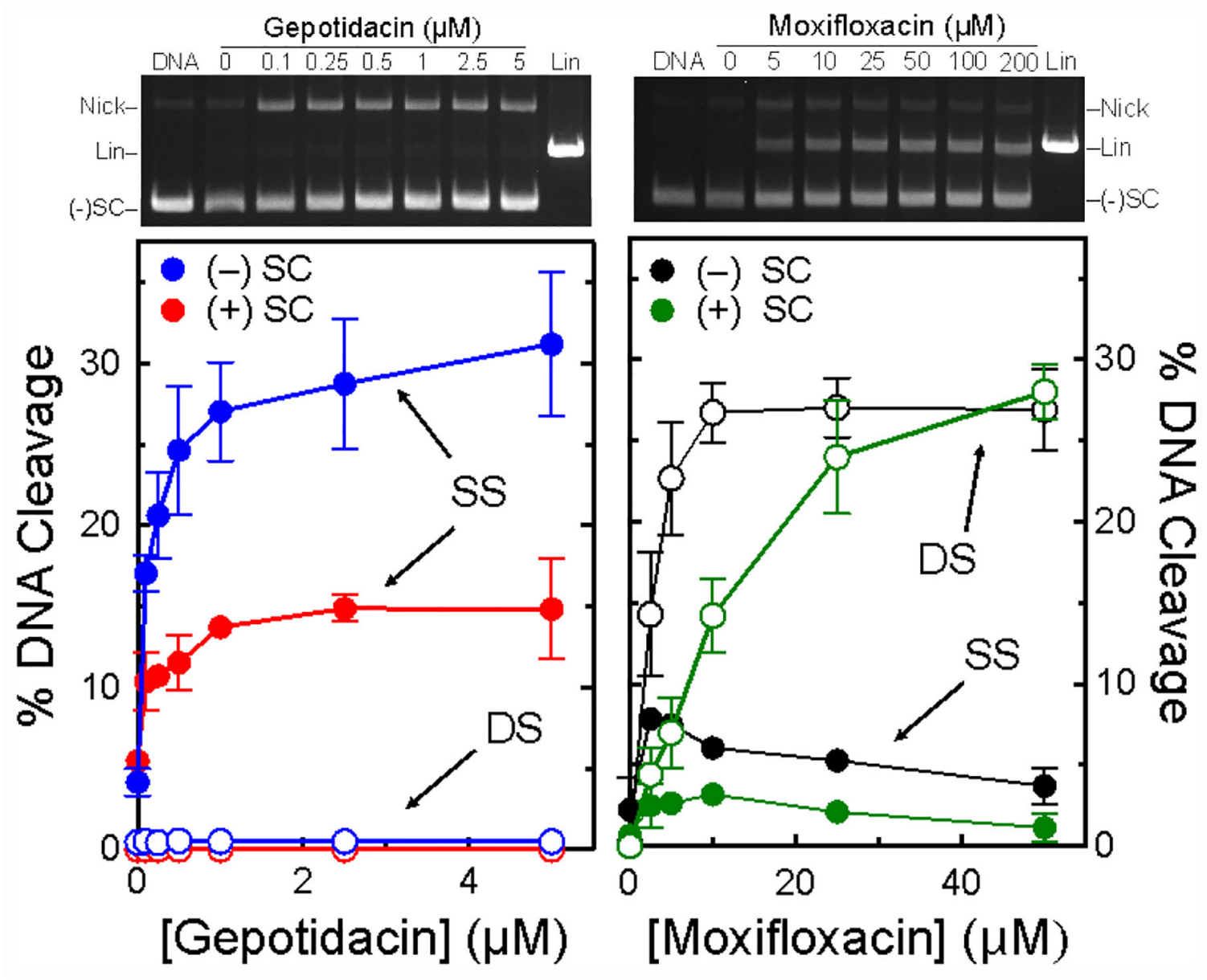

Figure 5:

Gepotidacin is a potent enhancer of gyrase-mediated single-stranded DNA cleavage. The left panel shows the effects of gepotidacin on $S$. aureus gyrase-mediated single- (SS, closed circles) and double-stranded (DS, open circles) DNA cleavage of negatively (blue) and positively (red) supercoiled DNA. The right panel shows the effects of moxifloxacin on gyrase-mediated single- and double-stranded DNA cleavage of negatively (black) and positively (green) supercoiled DNA. Error bars represent the SD of at least three independent experiments. The gels shown at the top are representative cleavage assays with negatively supercoiled DNA. The mobilities of negatively supercoiled DNA [(-)SC], nicked circular DNA (Nick), and linear DNA (Lin) are indicated on the gels. 


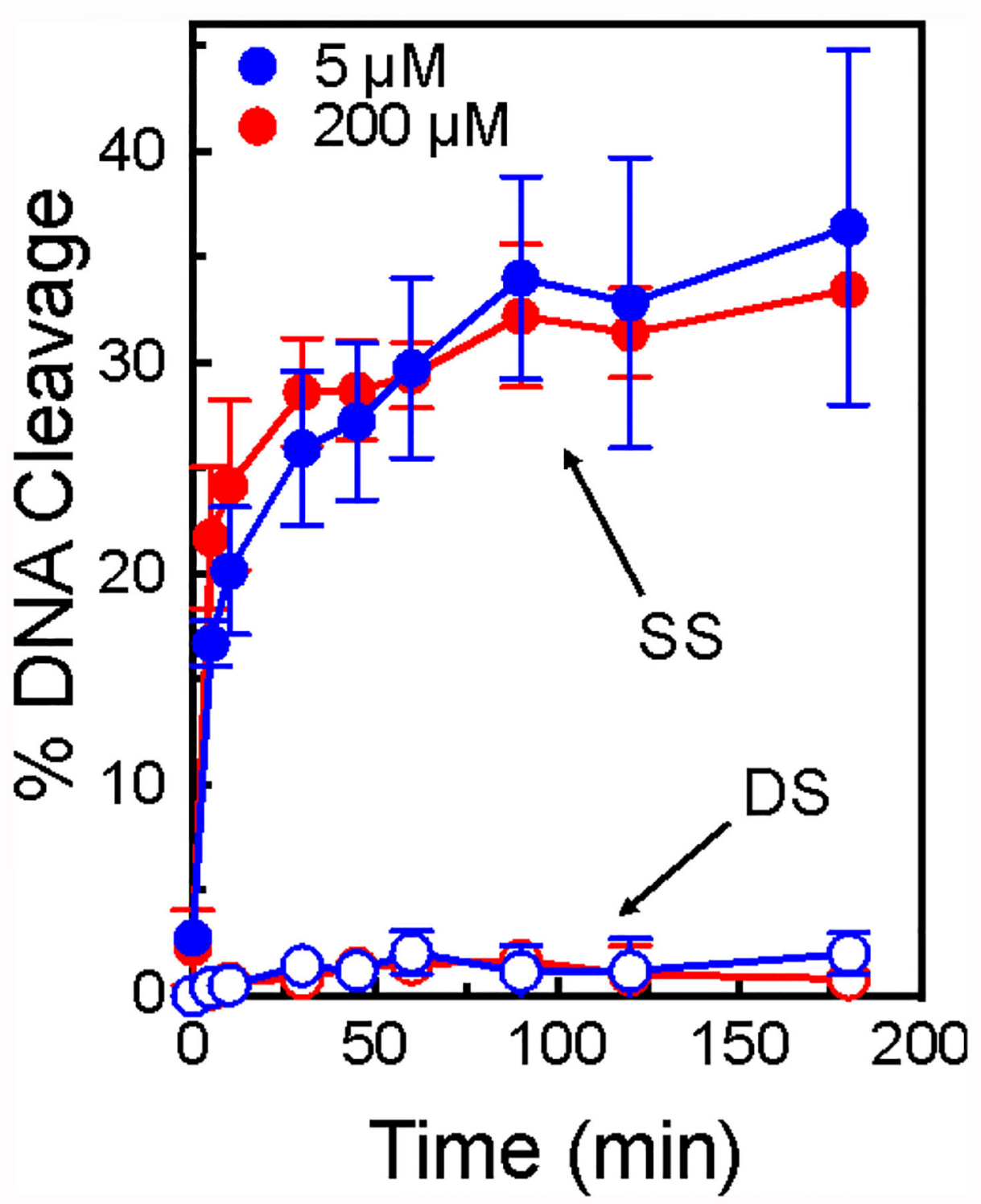

Figure 6:

Gepotidacin stabilizes only single-stranded DNA breaks mediated by $S$. aureus gyrase. The enhancement of single-stranded (SS, closed circles) and double-stranded (DS, open circles) DNA cleavage over time in the presence of $5 \mu \mathrm{M}$ (blue) and $200 \mu \mathrm{M}$ (red) gepotidacin are shown. Error bars represent the SD of at least three independent experiments. 


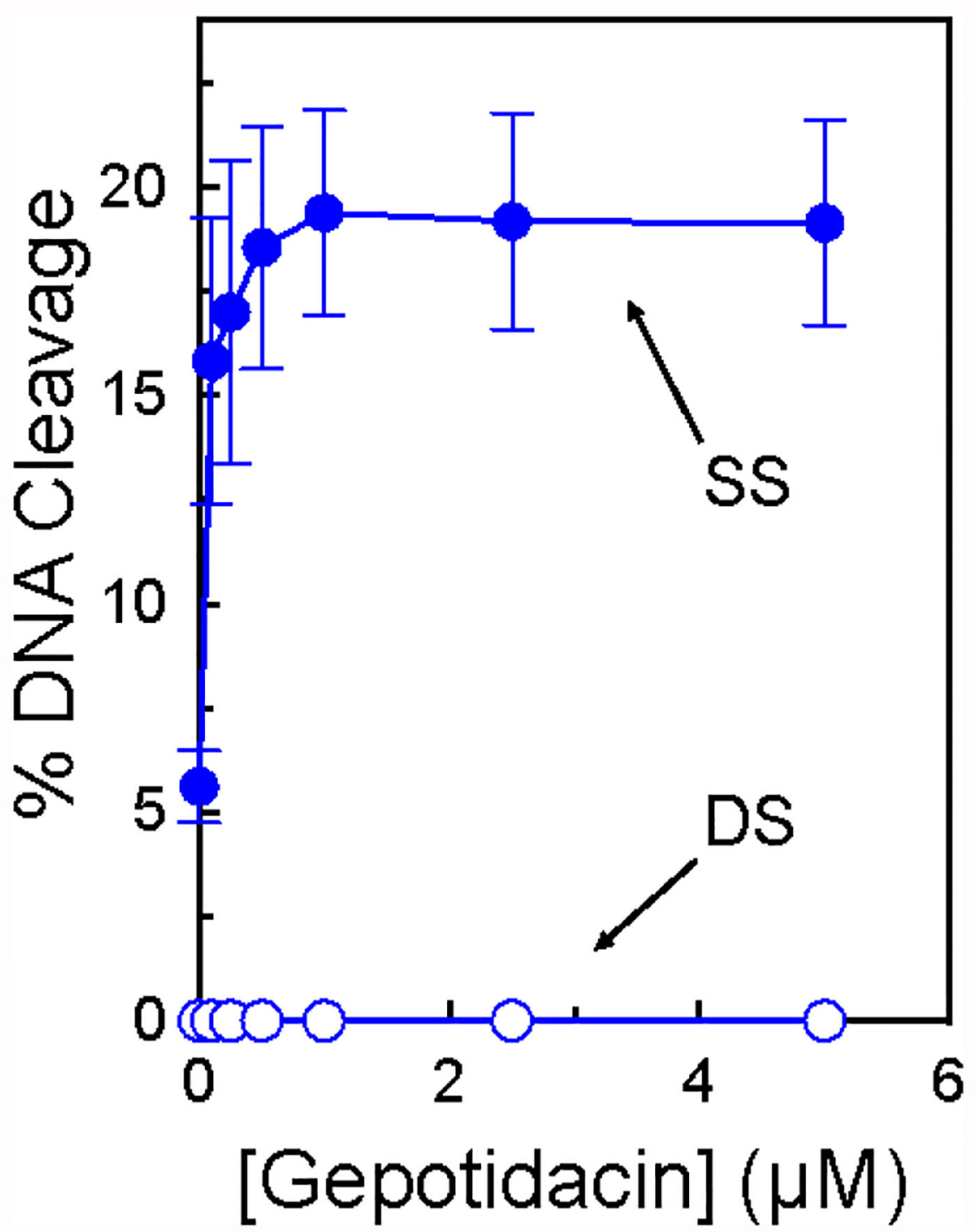

Figure 7:

Gepotidacin enhances only single-stranded DNA breaks mediated by $S$. aureus gyrase in the presence of ATP. The enhancement of gyrase-mediated single-stranded (SS, closed circles) or double-stranded (DS, open circles) DNA breaks generated by gyrase in the presence of $1.5 \mathrm{mM}$ ATP is shown. Error bars represent the SD of at least three independent experiments. 


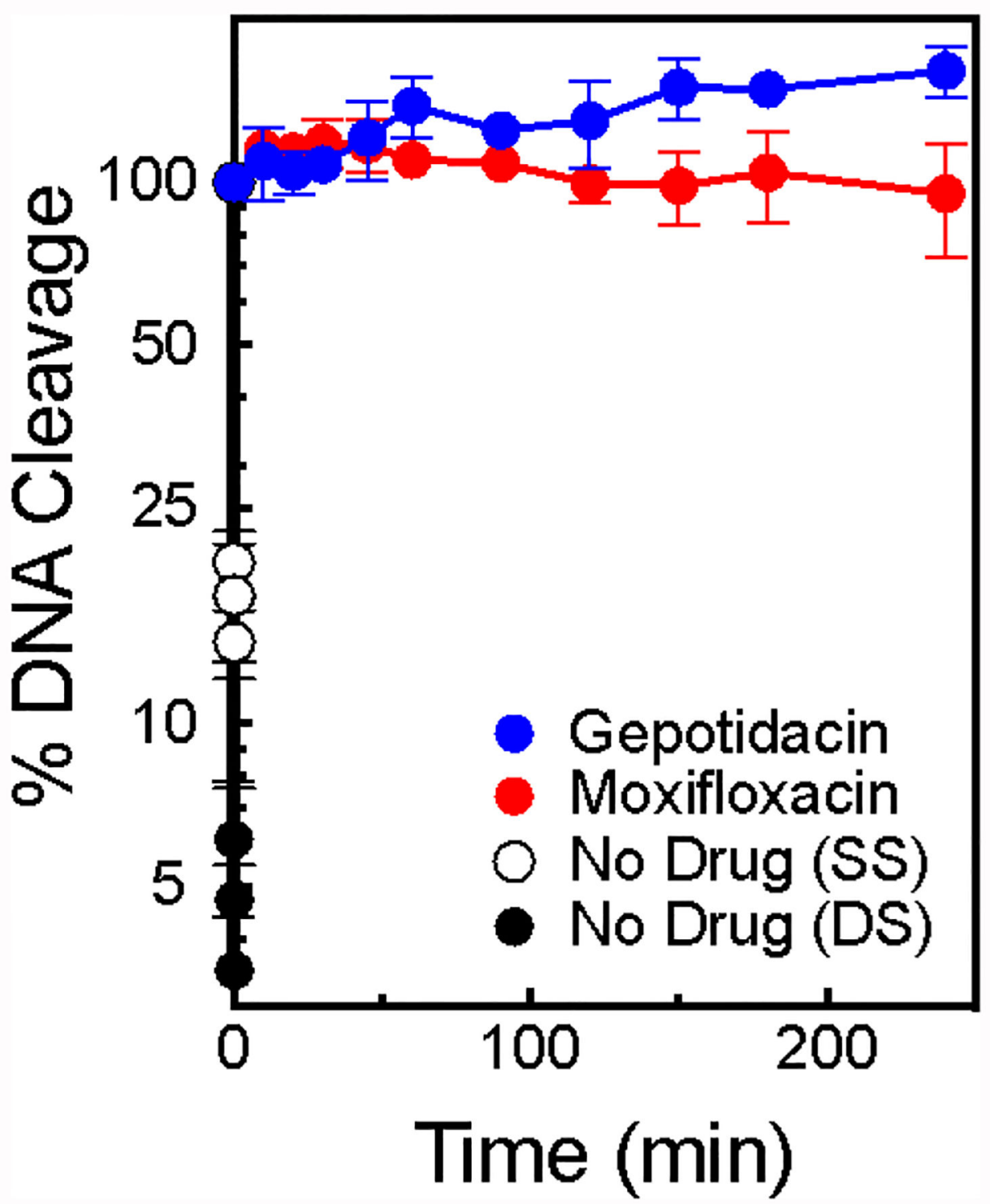

Figure 8:

Gepotidacin induces stable DNA cleavage complexes formed by $S$. aureus gyrase. The persistence of ternary gyrase-DNA-drug cleavage complexes was monitored by the loss of single-stranded DNA breaks in the presence of $5 \mu \mathrm{M}$ gepotidacin (blue) or double-stranded DNA cleavage in the presence of $25 \mu \mathrm{M}$ moxifloxacin (red), or the loss of single- (open circle, white) or double-stranded DNA cleavage in the absence of drug (closed circle, black). Levels of DNA cleavage were set to $100 \%$ at time zero to allow for direct comparisons. Error bars represent the SD of at least three independent experiments. 


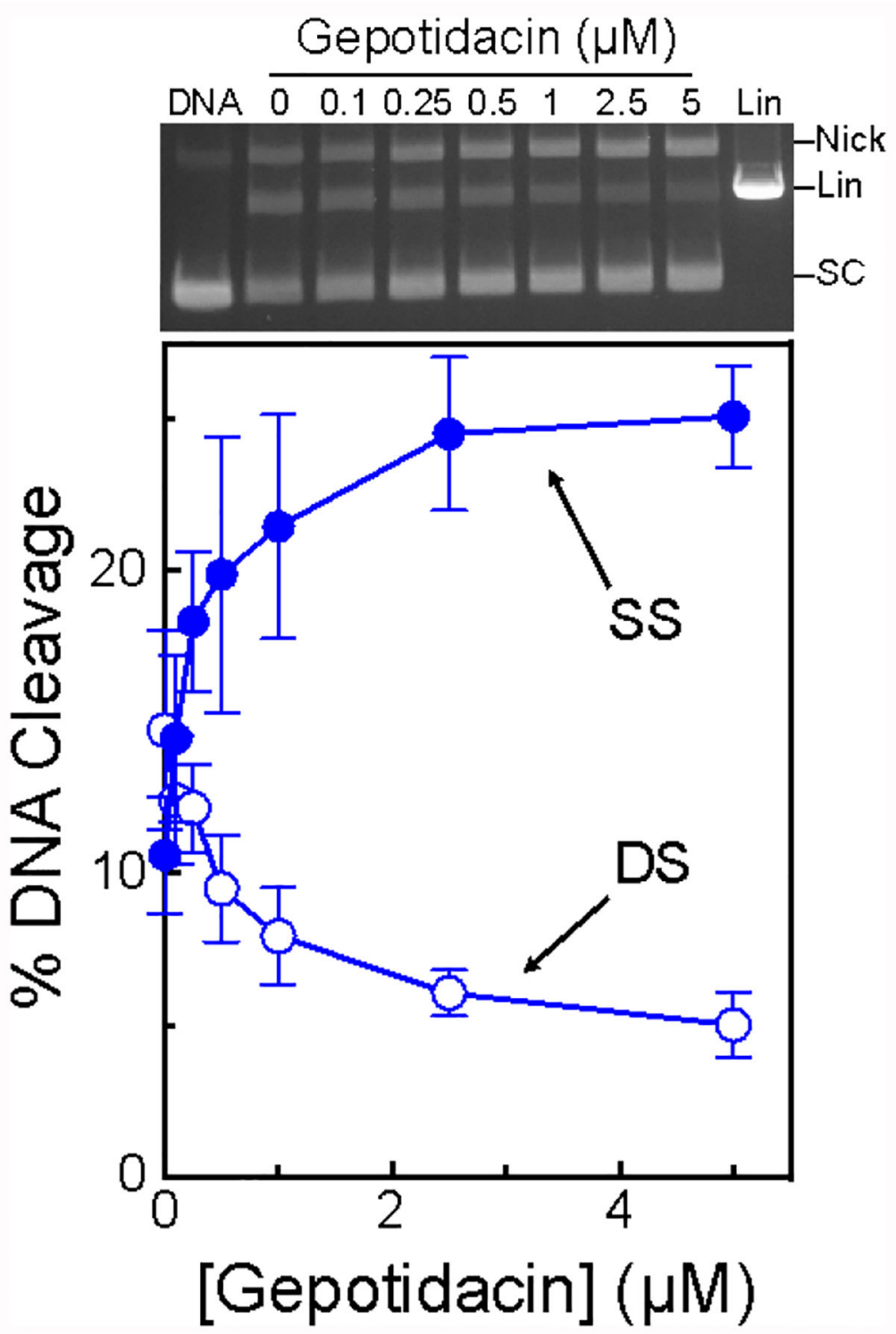

Figure 9:

Gepotidacin suppresses double-stranded DNA breaks generated by $S$. aureus gyrase. The effects of gepotidacin on $S$. aureus gyrase-mediated single-stranded (SS, closed circles) and double-stranded (DS, open circles) DNA cleavage are shown. Reactions were carried out in the presence of $\mathrm{Ca}^{2+}$ rather than $\mathrm{Mg}^{2+}$ to increase levels of baseline DNA cleavage. Error bars represent the SD of at least three independent experiments. The gel shown at the top is representative of at least three independent experiments. The mobilities of negatively supercoiled DNA [SC], nicked DNA (Nick), and linear DNA (Lin) are indicated on the gels. 


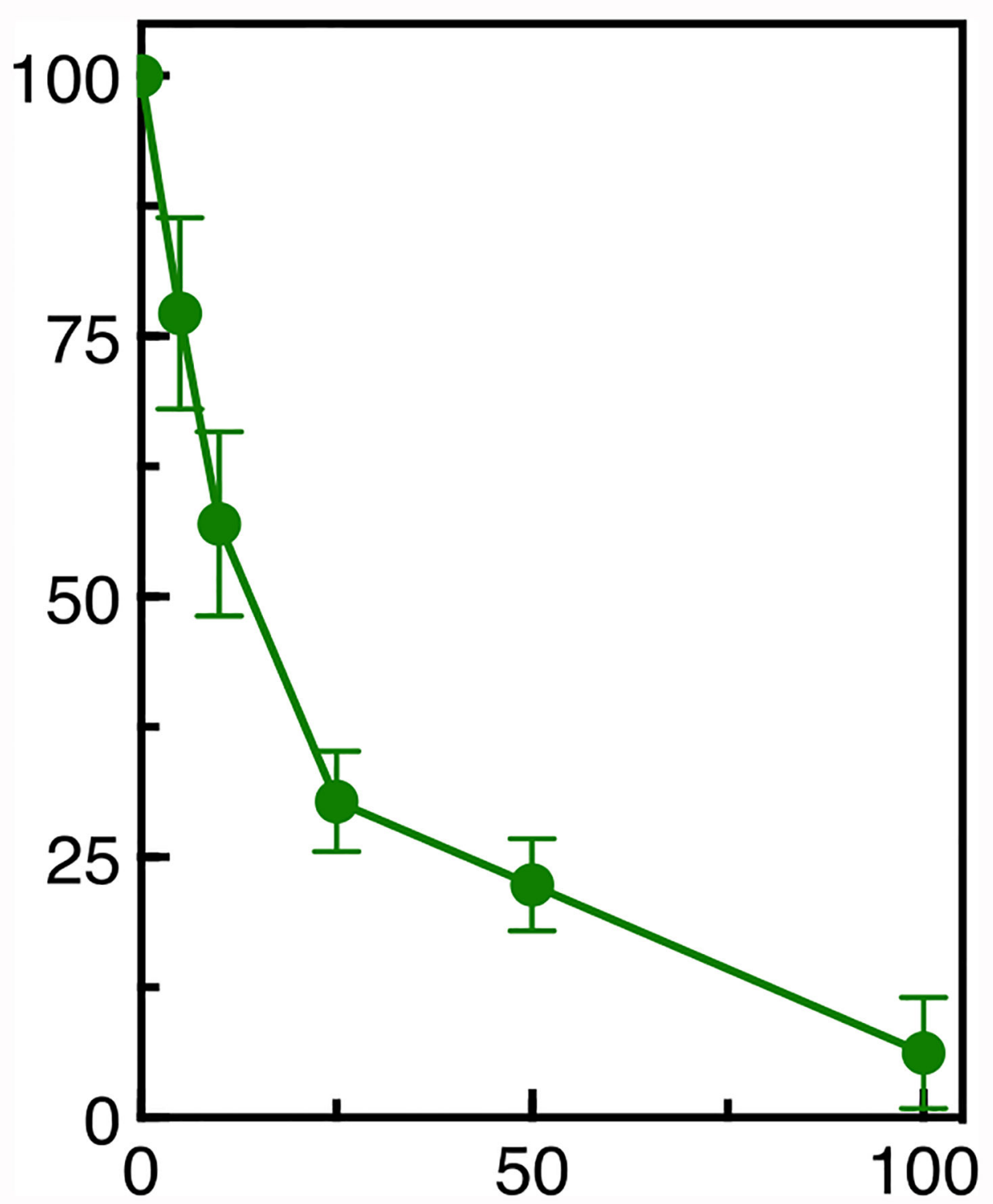

Figure 10:

The actions of gepotidacin and moxifloxacin on $S$. aureus gyrase-mediated DNA cleavage are mutually exclusive. A DNA cleavage/ligation equilibrium was formed in the presence of a saturating concentration of moxifloxacin $(25 \mu \mathrm{M})$ plus $0-100 \mu \mathrm{M}$ gepotidacin.

Competition was monitored by the loss of moxifloxacin-induced double-stranded DNA breaks. Error bars represent the SD of at least 3 independent experiments. 

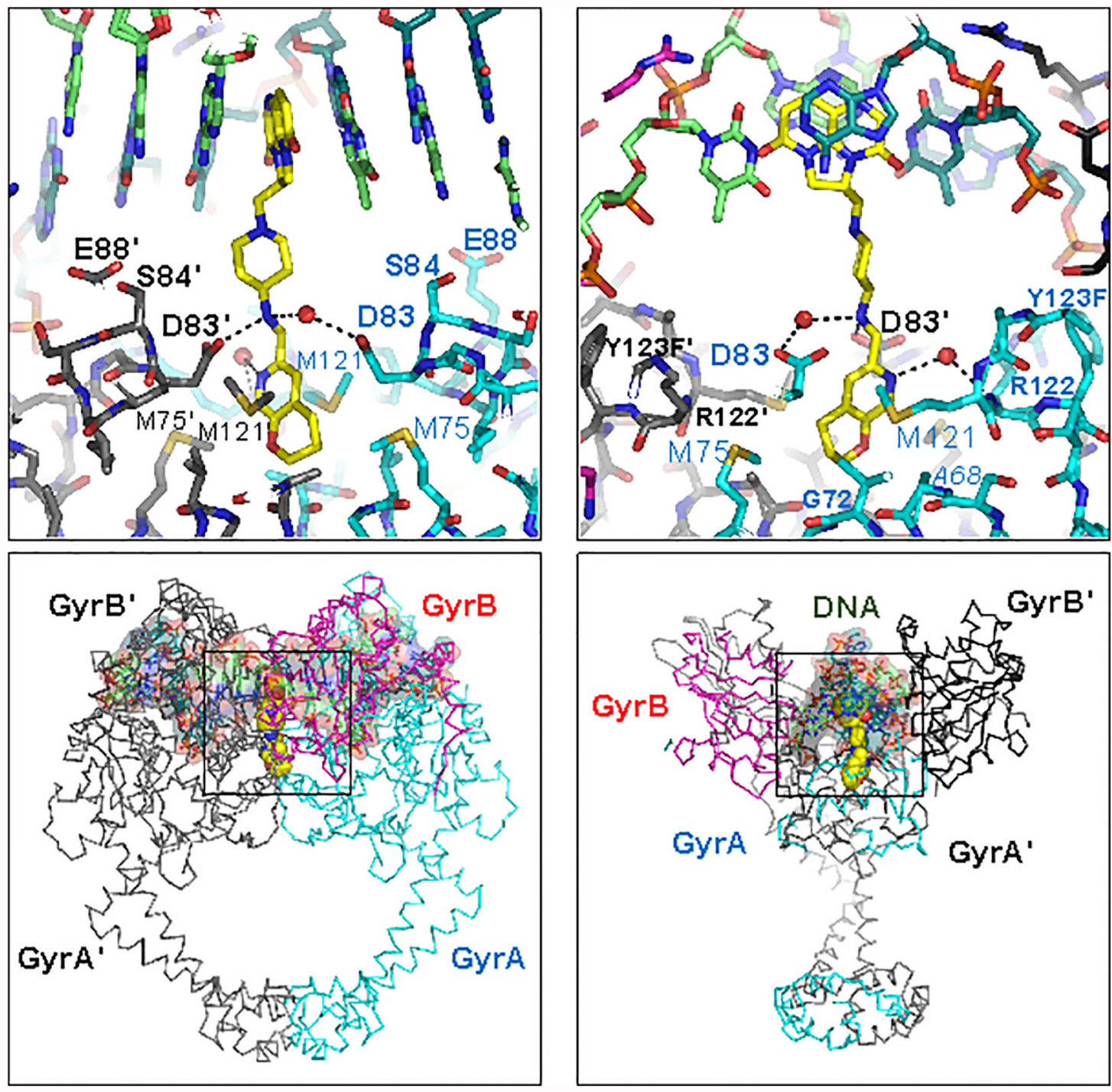

Figure 11:

Views of a gepotidacin complex formed with $S$. aureus gyrase and doubly nicked DNA at a resolution of $2.31 \AA$. The top left panel shows gepotidacin binding on the twofold axis of the complex midway between the two DNA cleavage sites; the top right panel is an approximately orthogonal $\left(90^{\circ}\right)$ view of the same structure. The bottom left and right panels show the same views as the corresponding top panels, but zoomed out to show the subunits of gyrase. In these panels, gepotidacin is shown as spheres, DNA with semi-transparent surface, and proteins as ribbons. In all panels, carbon atoms in the DNA are green, those in the first GyrBA core fusion truncate subunit are cyan/blue in GyrA and magenta in GyrB, and those in the second subunit are grey or black. Carbon atoms in gepotidacin are yellow, and oxygen, nitrogen, and sulfur atoms are red, blue, and yellow, respectively. Water molecules are shown as small red spheres. 

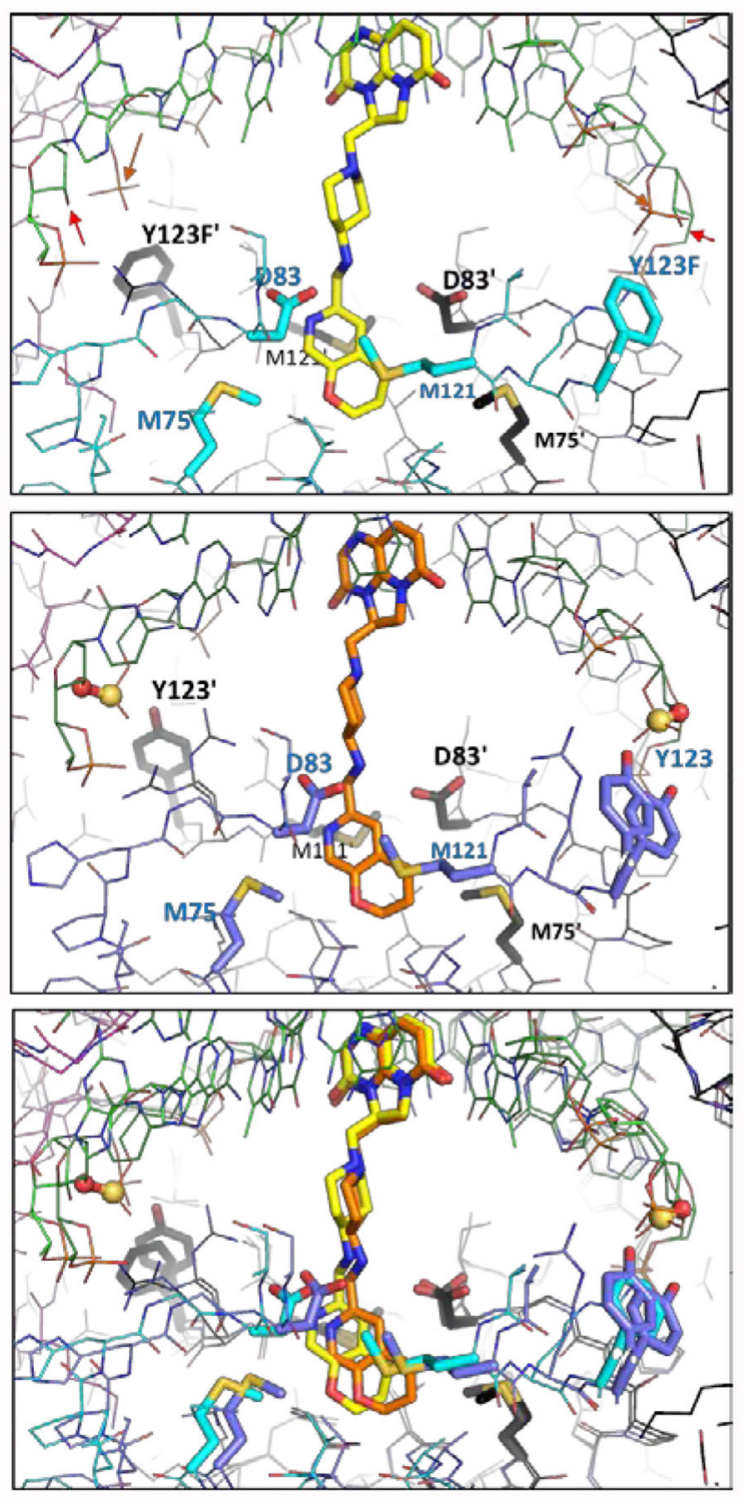

Figure 12:

Comparison of two gepotidacin crystal structures with $S$. aureus DNA gyrase and DNA. (top panel) A $2.31 \AA$ crystal structure of gepotidacin with doubly nicked DNA (atoms not bonded are arrowed). (middle panel) A $2.37 \AA$ crystal structure of gepotidacin with intact (uncleaved) DNA. (bottom panel) Structures from top and middle are superimposed based on GyrA subunits shown with grey/black carbons. Note the $\sim 1.2 \AA$ shift of atoms in the GyrA subunit with cyan/blue carbons and the similar shift in the right-hand side of gepotidacin. Colors are as shown in Figure 11, except that the carbon atoms in gepotidacin in the complex with intact DNA (middle and bottom panels) are shown in orange. 